\title{
Contigo o sin ti: medios no lucrativos y Estado desde la Ley 26.522
}

\author{
María Soledad Segura \\ Universidad Nacional de Córdoba
}

\section{Resumen}

Recibido: 14 de octubre de 2013. Aceptado: 24 de octubre de 2013.

La entrada en vigencia de la Ley 26.522 y las políticas de comunicación impulsadas desde entonces generan un nuevo espacio de posibilidades y desafíos para los medios del sector social. Frente a estas novedosas condiciones de producción, estos agentes colectivos desarrollan diversas estrategias y toman posiciones diferentes en los debates que se suscitan. En estas opciones pueden identificarse similitudes, pero también diferencias y rupturas. Una de las principales discrepancias se refiere al tipo de vínculo que se establece con el Estado. Se analizarán aquí las características de estas prácticas y se procurará comprenderlas/explicarlas habida cuenta del lugar de los agentes en el sistema mediático de relaciones de la Argentina a partir de 2010. Este problema se construye con una perspectiva teórico-metodológica interdisciplinaria que permite analizar las prácticas discursivas desde un enfoque sociohistórico y lleva a formularse la pregunta acerca de los agentes que las producen y de las condiciones dentro de las cuales llevan a cabo el proceso de su producción.

Palabras clave: medios sin fines de lucro, Estado, Ley 26.522, condiciones, estrategias, agentes.

\section{With or without you: nonprofit media and the State since Law 26.522}

\begin{abstract}
The coming into effect of Law 26.522, and the communication policies promoted since then, generate a new space of possibilities and challenges for the media of social sectors. Faced with these new conditions of production, collective agents develop diverse strategies and adopt different stances in the debates that arise. Among these options, one can identify similarities as well as differences and ruptures. One of the main discrepancies refers to the sort of link established with the State. We will analyze the characteristics of these practices and attempt to understand/explain them, given the location of these agents within the media relations system of Argentina since 2010. This problematic is built from a theoretical-methodological interdisciplinary perspective, which allows us to analyze discursive
\end{abstract}


practices from a socio-historical focus and leads us to formulate the question about the agents that produce them and the conditions within which they carry out the process of production.

Keywords: nonprofit media, State, Law 26.522, conditions, strategies, agents.

\section{Com ou sem você: mídia sem fins lucrativos e Estado desde a Lei 26.522}

\section{Resumo}

A entrada em vigor da Lei 26.522 e as políticas de comunicação requeridas desde então geram um novo espaço de possibilidades e desafios para o setor de mídia social. Confrontados com estas novas condições de produção, esses atores coletivos desenvolvem diferentes estratégias e assumem diferentes posições nos debates que surgem. Nessas opções podem ser identificadas semelhanças, mas também diferenças e rupturas. Uma das principais discrepâncias diz respeito ao tipo de vínculo estabelecido com o Estado. Vamos analisar aqui as características dessas práticas e procuraremos compreendê-las, conforme a localização dos agentes no sistema de relações da mídia da Argentina a partir de 2010. Este problema é construído a partir de uma teoria e método interdisciplinar que permite analisar as práticas discursivas de uma perspectiva sócio-histórica e leva a fazer a pergunta sobre os agentes que as produzem e as condições em que eles realizam o processo de produção.

Palavras chave: mídia social, Estado, Lei 26.522, condições, estratégias, agentes.

\section{Introducción}

Las regulaciones de la radiodifusión en el país configuraron históricamente un sistema comercial en el que se privilegiaba a los actores con fines de lucro (empresas mediáticas) como prestatarios del servicio, mientras se relegaba al Estado a un rol subsidiario y se excluía al sector social-comunitario (organizaciones no gubernamentales, sindicatos, fundaciones, cooperativas, organizaciones y movimientos sociales, etc. $)^{1}$. No obstante su ilegalidad, los medios comunitarios, populares y alternativos se desarrollaron en el país, en particular a partir de mediados de 1980, favorecidos por la introducción de la tecnología de la frecuencia modulada y por la apertura democrática.

\footnotetext{
1 Esto comenzó a configurarse así desde 1924 cuando se dictó la primera norma referida específicamente a radiodifusión hasta 2009 (Mastrini, 2009).
} 
Esta situación fue modificada por la Ley 26.522 de Servicios de Comunicación Audiovisual (LSCA) ${ }^{2}$ aprobada en octubre de 2009 y que entró en vigencia en marzo de $2010^{3}$. La nueva norma -además de establecer la desmonopolización, los límites a la concentración, los medios públicos y la protección a la producción nacional (Baranchuk \& Rodríguez Usé, 2011) - reconoce por primera vez a los actores no lucrativos como prestadores de servicios de radiodifusión y les reserva un tercio de las frecuencias radioeléctricas. Esto constituye la novedad comunicacional más importante desde la restitución del gobierno constitucional en la Argentina hace más de tres décadas.

La entrada en vigencia de la Ley 26.522 y las políticas de comunicación impulsadas desde entonces generan un nuevo espacio de posibilidades y desafíos para los medios del sector social. Frente a estas novedosas condiciones de producción, estos agentes colectivos desarrollan varias estrategias y toman posiciones diferentes en los debates que se suscitan. En estas opciones pueden identificarse similitudes, pero también diferencias y rupturas. Una de las principales discrepancias se refiere al tipo de vínculo que se establece con el Estado. Se analizarán aquí las características de estas prácticas y se procurará comprenderlas/explicarlas habida cuenta del lugar de los agentes en el sistema mediático de relaciones de la Argentina a partir de 2010.

Este problema se construye desde una perspectiva teórico-metodológica interdisciplinaria que nos permite analizar las prácticas discursivas desde un enfoque sociohistórico. Analizar las prácticas discursivas lleva a preguntarse sobre los agentes que las producen y de las condiciones dentro de las cuales llevan a cabo el proceso de su producción. Se plantea que las prácticas encuentran el principio de comprensión/explicación (Costa, 2010) en el lugar que define la identidad social y competencia de quienes los producen (Costa \& Mozejko, 2002). Así, las prácticas discursivas son comprensibles en tanto realización no necesariamente consciente ni racional de opciones dentro de un espacio de posibles, si se considera el lugar, la competencia y la gestión del agente social que las produce en un sistema de

\footnotetext{
2 En rigor, el artículo 45 del antiguo decreto-ley de radiodifusión 22.285 que impedía a las asociaciones sin fines de lucro prestar servicios de radiodifusión fue declarado inconstitucional por la Corte Suprema de Justicia de la Nación en 2004 y modificado por el Congreso de la Nación en 2005. No obstante, esta reforma continuó excluyendo de esta posibilidad a las cooperativas de servicios públicos en las zonas en las que hubiera un prestador privado.

3 La LSCA entró en vigencia seis meses después de promulgada, una vez sorteada la mayoría de las acciones interpuestas ante la Justicia con el fin de declarar su inconstitucionalidad o impedir su aplicación total o parcial (Corbière \& Güida, 2012).
} 
relaciones en un tiempo y espacio dados, en el marco de su trayectoria, independientemente de que su resultado sea o no rentable (funcional, legitimante) para él.

Desde este enfoque, se sostiene con Bourdieu (2000, p. 137) que las luchas simbólicas son las luchas políticas por excelencia y son inseparables de las luchas materiales por la dominación en la medida en que se disputa la imposición de la interpretación pública legítima sobre el orden social. La lucha simbólica es crucial a la hora de comprender y construir imágenes de mundo, de configurar proyectos de sociedad e identidades colectivas, de conocer y hacer. Aunque en grados diferentes, estas concepciones, convertidas en sentido común, sustentan las prácticas sociales, culturales y políticas. A través de este sistema, el orden social es susceptible no solo de ser reproducido sino también impugnado. En nuestras sociedades mediatizadas, los medios de comunicación de masas ocupan una posición central - aunque no determinante - en estas disputas (Mata, 1999; Verón, 1998; Sodré, 1998, entre otros).

Entonces, lo que está en juego en el sistema mediático es el control de las representaciones sobre lo común producidas y puestas a circular en los medios de comunicación de masas. De este modo, el objeto de la disputa en el espacio público es el poder relativo de cada agente en el campo específico de producción y puesta en circulación de representaciones sobre lo común en los medios de comunicación de masas y, por lo tanto, su capacidad diferenciada de relación en el espacio público. De allí la importancia que los agentes otorgan a las reglas que regulan esta competencia por imponer las representaciones legítimas sobre el orden social, ya sea para subvertirlas o conservarlas. Estas normas definen buena parte de los recursos que fundan la mayor o menor probabilidad de influencia de cada agente, es decir que inciden fuertemente en la generación de su poder relativo. Por lo tanto, poseer el control de la definición, interpretación y aplicación de las reglas significa tener, en buena medida, el control de las prácticas.

Es por esta razón que otros autores (Segura, 2011) sostuvieron que las prácticas de las organizaciones sociales - en particular, de los medios sin fines de lucro, como principales impulsoras del proceso político que culminó en la sanción de la Ley de Servicios de Comunicación Audiovisual- se hacen comprensibles al considerar el lugar social que ocupaban en relación con los otros dos sectores de la radiodifusión. A pesar de su gran diversidad, su inserción local y territorial, su histórica lucha por la inclusión legal en el sistema comunicacional de cada país y su enorme trabajo cotidiano, el sector no lucrativo es el menos poderoso de los tres 
sectores de la radiodifusión. En particular, las condiciones económicas y legales de las organizaciones sociales constituyeron sus dos flancos históricamente débiles para prestar servicios de radiodifusión. Se trata, además, del sector menos visible de las industrias culturales ${ }^{4}$. Dado su lugar de menor poder relativo con respecto a las empresas mediáticas y del Estado, impulsaron cambios en las reglas de un juego (las del sistema de medios) en el que tenían muy limitadas posibilidades de ejercer la palabra.

A partir de la entrada en vigencia de la Ley 26.522, la opción más notable y común a la mayoría de los canales y productoras audiovisuales del sector no lucrativo consiste en nuclearse en entidades de mayor grado para mejorar su capacidad de relación con respecto al Estado y los medios privados. Esta estrategia tiende a: 1) incidir para que el Estado profundice los cambios en las reglas de juego al implementar la Ley de Servicios de Comunicación Audiovisual por medio de regulaciones y políticas que favorezcan la participación del sector socio-comunitario; y 2) asegurar su propia sostenibilidad y su desarrollo.

En primer lugar, se caracterizarán las nuevas posibilidades y limitaciones que la regulación y las políticas de comunicación abren para el sector social con la entrada en vigencia de la Ley 26.522. Luego se abordarán las prácticas discursivas producidas por las articulaciones de canales y productoras audiovisuales sin fines de lucro que se conformaron en la Argentina a partir de 20105 (Trama Audiovisual, Federación Cooperativa de Productores de Contenidos Audiovisuales (FECOOPTV) y Espacio Abierto de Televisoras Alternativas, Populares y Comunitarias ${ }^{6}$ ) y se identificarán sus coincidencias y divergencias. En tercer término, se reconstruirá el lugar de los agentes colectivos que producen estas opciones en el marco de un sistema de relaciones. Finalmente, se pondrán en relación estos términos para comprender las opciones de los agentes.

\footnotetext{
4 Ni las entidades que las nuclean ni los organismos estatales del área cuentan con información centralizada, sistematizada y completa sobre ellas.

5 A pesar de su ilegalidad, las radios del sector no lucrativo están más consolidadas: tienen una trayectoria de casi 30 años de prestación de servicios de modo que demostraron poder sostenerse en el tiempo en condiciones adversas y fueron las impulsoras de la reforma en políticas de comunicación. La mayoría de las radios comunitarias, populares y alternativas, al momento de ser sancionada la nueva ley, ya estaban nucleadas en el Foro Argentino de Radios Comunitarias (FARCO) surgido en 1985 o bien en la Red Nacional de Medios Alternativos (RNMA) constituida en 2004. Sobre sus estrategias a partir de 2010 véase: Iglesias \& Leavi, 2013.

6 En 2011 se conformó también la Coordinadora en Defensa de la Comunicación Comunitaria, Alternativa y Popular (COORDECCAP). Si bien hizo la primera manifestación frente a la sede de Autoridad Federal de Servicios de Comunicación Audiovisual (AFSCA), tuvo una existencia efímera.
} 


\section{El escenario}

Al concentrarse en el estudio de las tomas de posición de las asociaciones de medios y productoras audiovisuales sin fines de lucro a partir de 2010 se hace necesaria la descripción de las condiciones objetivas dentro de las cuales estos agentes colectivos realizaron sus opciones.

En este apartado se reconstruyen algunas condiciones estructurales: 1) las regulaciones y políticas de comunicación establecidas desde 2010, que definen funciones de los agentes participantes del sistema, y 2) la estructura del mercado mediático, que define los modos de participación en el juego y el acceso a recursos.

\subsection{Nuevas regulaciones y políticas}

La entrada en vigencia de la Ley de Servicios de Comunicación Audiovisual aprobada en 2009 configura un nuevo espacio de posibles para estas organizaciones al reservar un 33\% del espectro radioeléctrico para entidades sin fines de lucro, a las que reconoce como uno de los tres sectores prestadores de radiodifusión (LSCA, art. 21). En la reglamentación se define como tales a: "las cooperativas, mutuales, fundaciones y asociaciones definidas como tales por las normas vigentes", lo cual excluye a las organizaciones sociales sin personería jurídica (Decreto Reglamentario 1225/2010 de LSCA, art. 21, inc. b). Además, al no establecer diferencias entre ellas, iguala las experiencias dependientes de grandes fundaciones empresarias, empresas cooperativas y emprendimientos comunicacionales de organizaciones sociales, lo que pone a estos últimos en situación de mayor desventaja para el acceso a licencias y a financiación ${ }^{7}$.

A estas entidades la ley no les impone restricciones adicionales de potencia ni de alcance geográfico ${ }^{8}$ y reconoce explícitamente su derecho a asegurar su sustentabilidad económica, independencia y desarrollo, a cuyos efectos deben poder ob-

\footnotetext{
En el artículo 4 de la Ley de Servicios de Comunicación Audiovisual se define a las "emisoras comunitarias" como "actores privados que tienen una finalidad social y se caracterizan por ser gestionadas por organizaciones sociales de diverso tipo sin fines de lucro. Su característica fundamental es la participación de la comunidad tanto en la propiedad del medio como en la programación, administración, operación, financiamiento y evaluación. Se trata de medios independientes y no gubernamentales. En ningún caso se la entenderá como un servicio de cobertura geográfica restringida". Sin embargo, en el resto del articulado no vuelven a ser mencionadas como tales. 8 La Ley de Servicios de Comunicación Audiovisual sí impone a los medios de comunicación audiovisual sin fines de lucro las mismas restricciones que tienen los licenciatarios con fines de lucro (por ejemplo, tope a la cantidad de licencias y cobertura de mercado del 35\%).
} 
tener recursos de subsidios, donaciones, aportes solidarios, auspicios, patrocinios y publicidad privada y oficial ${ }^{9}$.

Además, la ley establece cuotas de pantalla en todos los canales para la producción local, nacional, independiente, propia y de contenidos educativos y culturales (LSCA, art. 65). Estos cupos conllevan la necesidad de todos los canales - cualquiera sea su tipo de propiedad- de disponer de producciones con estas características y, así, implican una mayor demanda de lo que productoras audiovisuales del sector social pueden ofrecer. Sin embargo, también constituyen un piso mínimo requerido que se exige también a los canales del sector social, televisoras que cuentan con menores recursos económicos y tecnológicos para producir ${ }^{10}$. Por lo tanto, esta disposición significa tanto una posibilidad para algunos actores del sector como una limitación para otros.

No obstante estos reconocimientos, la ley no prevé sistemas de estímulo a la producción y consolidación del sector sin fines de lucro, aunque faculta al Poder Ejecutivo Nacional a "desarrollar líneas de acción destinadas a fortalecer el desarrollo sustentable del sector audiovisual" en general (LSCA, art. 153). Establece también que parte de los fondos recaudados por la Autoridad Federal de Servicios de Comunicación Audiovisual (AFSCA) debe destinarse a la radiodifusión comunitaria: "El diez por ciento (10\%) para proyectos especiales de comunicación audiovisual y apoyo a servicios de comunicación audiovisual, comunitarios, de frontera, y de los pueblos originarios, con especial atención a la colaboración en los proyectos de digitalización" (LSCA, art. 97, inc. f) ${ }^{11}$.

Desde la entrada en vigencia de la ley, varios organismos gubernamentales desarrollaron acciones en el primer sentido: el Ministerio de Desarrollo Social, el Ministerio de Planificación, el Programa de Polos Audiovisuales, el Banco

\footnotetext{
9 En varios países de la región, las entidades sin fines de lucro están legalmente excluidas de prestar el servicio (Guatemala, México, Paraguay) y en otros se las autoriza con restricciones que limitan su área de cobertura y sus fuentes de financiamiento de tal modo que les impiden sobrevivir (Chile, Brasil). No obstante, desde 2004, las nuevas legislaciones de radiodifusión comenzaron a reconocerlas como prestadoras del servicio y les reservan parte del espectro radioeléctrico (Venezuela, Uruguay, Argentina, Bolivia).

${ }_{10}$ Los servicios de radiodifusión televisiva abierta deberán emitir diariamente un mínimo del sesenta por ciento $(60 \%)$ de producción nacional; un mínimo del treinta por ciento $(30 \%)$ de producción propia que incluya informativos locales; un mínimo del treinta por ciento (30\%) de producción local independiente cuando se trate de estaciones localizadas en ciudades con más de un millón quinientos mil (1.500.000) habitantes. Cuando se encuentren localizados en poblaciones de más de seiscientos mil (600.000) habitantes deberán emitir un mínimo del quince por ciento (15\%) de producción local independiente y un mínimo del diez por ciento (10\%) en otras localizaciones (LSCA, art. 65).

11 Solamente en Canadá hay una reserva de parte del presupuesto del ente recaudador de radiodifusión para radios comunitarias y solo alcanza el dos por ciento (2\%) (AMARC, 1990).
} 
de Contenidos Universales Audiovisuales Argentino (BACUA), el Árbol de Contenidos Universales Argentino (ACUA) y el Instituto Nacional de Cine y Artes Audiovisuales (INCAA). En particular, para fomentar la producción audiovisual por parte de organizaciones comunitarias, la AFSCA y el CENOC (Centro Nacional de Organizaciones de la Comunidad) firmaron un convenio de cooperación en cuyo marco lanzaron en mayo de 2013 un concurso de spots de radio y cortos de televisión. Todas estas medidas fortalecen la producción y la distribución de productos audiovisuales, pero no la creación ni el mantenimiento sustentable de canales y señales de televisión, así como tampoco el sostenimiento de una programación coherente y estable con nuevos contenidos y estéticas.

En esa dirección, se comenzó a avanzar muy recientemente cuando la AFSCA y el Banco Nación en noviembre de 2012 firmaron un convenio para ofrecer créditos a todos los prestadores de servicios de comunicación audiovisual: grandes empresas, cooperativas, pymes, microempresas o asociaciones sin fines de lucro. Estos préstamos sirven para la creación y fomento de nuevos medios audiovisuales que deseen obtener licencias o para la adecuación técnica de los existentes. En el mismo mes, la AFSCA estableció un convenio con el Fondo Nacional de las Artes mediante el cual comenzaron a otorgar subsidios y créditos a actores con y sin fines de lucro en 2013.

En 2011, la AFSCA resolvió el llamado a concurso de 220 licencias para prestar servicios de comunicación audiovisual por televisión digital abierta, la mitad de las cuales serían para organizaciones sin fines de lucro (Res. 685 y 686). En la historia de la radiodifusión argentina este fue el primer llamado a concurso de licencias para televisión que hubiera ampliado las posibilidades de acceso a un nuevo tipo de prestadores. Sin embargo, el costo de los pliegos (de 42 mil a 140 mil pesos) y del alquiler de antena a ARSAT (Empresa Argentina de Soluciones Satelitales) ${ }^{12}$ (24 mil pesos mensuales) resultó demasiado alto para las organizaciones sociales; en particular, para las de menor desarrollo. Además, se solicitaba la declaración de empleados y la obligación de establecer relación de dependencia laboral con locutores o programadores, requisitos acordes con la regulación laboral argentina, pero que desconocen que muchas de estas entidades funcionan con trabajo voluntario y militancia. Ante las protestas que la medida suscitó se produjo una nueva convocatoria para que las televisoras existentes pudieran reservar una frecuencia

\footnotetext{
12 Es relevante que - a diferencia de otros países de la región - sea el Estado el encargado de desarrollar la infraestructura de transmisión a través de la empresa ARSAT (Calicchio, 2011).
} 
de baja potencia y participar de un concurso con pliegos que se suponía que irían de los 2 mil a los 5 mil pesos, en los que se quitaba el canon a abonar a ARSAT y se establecía la posibilidad de seguir transmitiendo en analógico mientras migraban al digital en un tiempo más prolongado (Res. 1465). Sin embargo, el requerimiento de que las televisoras contaran con infraestructura propia para la emisión digital resultó igualmente onerosa para estas entidades. Finalmente, en julio de 2012 la AFSCA reconoció los problemas y postergó la convocatoria de los concursos (Res. 929 y 930$)$.

En tanto, sin haber resuelto el problema de garantizar la efectiva ocupación del tercio del espectro radioeléctrico por parte del sector social, la prioridad del gobierno en materia de políticas de comunicación fue la adecuación de los grandes grupos mediáticos existentes a las disposiciones de la ley, en particular, que cada uno de los alrededor de 20 grupos empresarios cuya conformación actual excede los límites establecidos por la normativa, presente su plan de desinversión (LSCA, art. 161). Si bien, esta adecuación - y las desinversiones que implica- es condición necesaria para fomentar el pluralismo y la diversidad de medios, no es suficiente para asegurar el ingreso de actores sin fines de lucro al sistema mediático. Por el contrario, los planes empresarios presentados hasta el momento - de todos los grupos que excedían los límites establecidos por la ley, salvo el Grupo Clarín, que a fines de 2012 fue beneficiado por una medida cautelar que suspendía el plazo de desinversión hasta tanto se resolviese la cuestión judicial de fondo-y avalados por el Estado, implican transferencias entre privados, en muchos casos la mera división del capital entre los socios del conglomerado.

La indefinición hasta el presente del conflicto con el Grupo Clarín abre una nueva posibilidad a los medios del sector no lucrativo de instalar el debate ante el gobierno sobre su legalidad y sustentabilidad, es decir, sobre la necesidad de llamados a licitación de frecuencias adecuados a su perfil y de planes de promoción de su actividad ${ }^{13}$.

Con una legislación nueva y parcialmente implementada, cuyas prescripciones aún no están consolidadas como normas puestas en funcionamiento, se abre un mayor espacio de posibilidades para la acción estratégica de los agentes del campo.

13 En ese marco, FARCO, Usina de Medios y otras entidades organizaron mesas de debate con representantes de la AFSCA y especialistas sobre estos temas en el Mercado de Industrias Culturales (MICA) y en otras instancias. 


\subsection{No tan nueva concentración}

La estructura del sistema de medios de comunicación en el país se caracteriza por la multiplicación de soportes mediante la convergencia tecnológica (audiovisual, informática y de telecomunicaciones) y por la concentración de la propiedad ${ }^{14}$ en pocos pero grandes grupos ${ }^{15}$. Estos niveles -inéditos en la historia argentinade concentración de la propiedad de los medios tuvieron como efectos más evidentes la retracción de la diversidad de fuentes, la tendencia a la uniformidad de la agenda informativa, la modernización tecnológica en la organización de la producción, la precarización de los procesos de trabajo y la centralización geográfica de la producción de contenidos ${ }^{16}$ (Mastrini \& Becerra, 2006; Becerra \& Mastrini, 2009). Se registra, asimismo, una confluencia de intereses económicos directos e indirectos entre las empresas periodísticas y otros sectores de producción.

En 2009, los principales grupos de medios eran: Clarín (en prensa escrita, televisión abierta y TV por cable, radio y agencias de noticias, entre otras), Telefónica (telecomunicaciones y televisión abierta), Vila-Manzano-De Narváez (televisión por cable, TV abierta y prensa escrita, entre otros) y Hadad (radio y prensa escrita) (Becerra y Mastrini, 2009, p. 60). Estos cuatro primeros operadores concentraban en promedio el $84 \%$ de la facturación y el $83 \%$ del dominio del mercado de medios de la Argentina en $2004^{17}$. Este alto nivel de concentración se agrava porque estas firmas pertenecían generalmente a "los mismos dueños que están ramificados en todas las hileras productivas en casi la totalidad de las industrias consideradas". En particular, "Clarín y Telefónica se destacan como grupos dominantes, si bien en algún caso existen grupos emergentes". En 2004, un tercio del mercado (35\%) era controlado por el primer operador. El Grupo Clarín era el principal multimedio de la Argentina, "con las sinergias que en materia de línea editorial, promoción

\footnotetext{
14 La concentración de la producción puede definirse de acuerdo con la incidencia que tienen las mayores empresas de una actividad económica en el valor de producción de la misma. La concentración puede ser horizontal o monomedia (en la misma actividad), vertical (abarca distintas fases de la producción) o diagonal o conglomeral (diversifica fuera de la rama de origen) (Becerra \& Mastrini, 2009, p. 30-32).

15 Esta situación se reitera en gran parte de las esferas productivas (Becerra \& López, 2009, p. 21; Oliva, 2008).

16 El principal peligro de la concentración es la tendencia de los mercados a configurar regímenes de oligopolio o monopolio, situación que se produce cuando no operan las reglas propias de la fase concurrencial y, en su lugar, unas pocas empresas de gran dimensión ocupan la totalidad del mercado reduciendo las opciones disponibles (Becerra \& Mastrini, 2009, p. 30).

17 Para medir la concentración, Becerra y Mastrini (2009) toman como referencia los índices CR4 y CR8 (CR = concentration ratio), que permiten identificar los porcentajes de concentración de mercado de las cuatro $\mathrm{u}$ ocho principales empresas del sector y posibilitan construir tendencias estables a lo largo del tiempo. Asimismo, construyen indicadores relativos al primer operador de cada sector y establecen promedios generales por país e industria.
} 
de temas, productos y oclusión de otros, ello supone" (Ibíd., p. 73) ${ }^{18}$. La tendencia entre los indicadores de concentración del año 2000 y los de 2004 mostraba "un aumento que profundizaba la participación de menos actores en posiciones cada vez más dominantes" (Ibíd., p. 72-73).

Además, a partir de 2002 aparecieron nuevos diarios y semanarios gráficos y digitales "de baja tirada, sin impacto masivo en el consumo, pero que diversificaron el panorama" (entrevista realizada por María Eugenia Ludueña a Guillermo Mastrini, [Ludueña, 2010, p. 269]). Entre ellos, el diario Crítica de la Argentina, dirigido por Jorge Lanata, surgió el 2 de marzo de 2008 y cerró en mayo de 2010 a pesar de la larga resistencia de sus trabajadores. También, a partir de 2004, el exbanquero Sergio Szpolski construyó un multimedio en pocos años por medio de la posesión o control de medios caracterizados por su orientación oficialista. Adquirió la revista Veintitrés y Veintitrés Internacional. En marzo de 2008 lanzó el diario Diagonales en La Plata. Dos meses después sacó el diario gratuito $E l$ Argentino y el semanario Miradas al Sur con circulación principal en la ciudad de Buenos Aires y en el Gran Buenos Aires. En noviembre del mismo año, la empresa Electroingeniería compró Radio del Plata y puso a Szpolski como su director comercial. En febrero de 2009 adquirió también Radio América y FM Aspen. En 2009 publicó el diario Tiempo Argentino, la edición local de la revista Lonely Planet, La Gaceta del Cielo (que se distribuye en los aviones de Aerolíneas Argentinas), se asoció a la edición internacional de la revista Newsweek, la revista Siete Días (Szpolski..., 2010), la licencia del canal de cable CN23 y la revista Contraeditorial. Todos estos medios en general "simpatizan con el gobierno y reciben abundante publicidad oficial" (Ludueña, 2010, p. 267). Otros empresarios de medios en ascenso y favorecidos por el gobierno nacional fueron Hadad, Vila-Manzano y Cristóbal López (Becerra, 2013; Piccone, 2011) ${ }^{19}$.

\footnotetext{
18 En 2004, el diario Clarín lideraba el mercado de la prensa diaria, concentraba el 31\% de la circulación de periódicos y mantenía una enorme diferencia en circulación (417 mil ejemplares diarios) con su inmediato competidor, La Nación (185 mil ejemplares diarios). Esta competencia se realizaba entre socios comerciales en CIME$\mathrm{CO}$, propietario de periódicos de amplia circulación y tradición en el interior; en la agencia noticiosa Diarios y Noticias (DyN) y junto con el Estado nacional en la principal productora de papel de diario del país: Papel Prensa S.A. Además, Clarín dominaba casi la totalidad del mercado de los avisos clasificados y el $40 \%$ de la facturación publicitaria. Poseía también la mayoría de las acciones del principal diario gratuito del país: La Razón. Todo esto reforzaba la centralidad de Clarín como "referencia para la construcción de la agenda pública mediática" (Becerra \& Mastrini, 2009, p. 65-66).

19 El apoyo a medios como los de Szpolski o Hadad constituyó estrategias del gobierno a partir de que el conflicto por la Resolución 125 hubiera demostrado que "la política comunicacional [anterior a 2008] no era la correcta" (Piccone, 2011).
} 
En tanto, las gestiones de gobierno de Néstor Kirchner y Cristina Fernández tendieron a fortalecer el sistema de medios estatales y reposicionarlos en el mercado de medios. Se pusieron en marcha nuevas iniciativas de televisión pública. En 2004, se firmó el acuerdo de inclusión de la Argentina en la televisora sudamericana Telesur, emprendimiento comunicacional multiestatal impulsado por el gobierno venezolano y con la participación accionaria mayoritaria de Venezuela, seguida por la Argentina, Cuba, Uruguay y Bolivia, que salió al aire el 24 de julio de 2005. Se creó en 2005 el canal Encuentro dependiente del Ministerio de Educación, Ciencia y Tecnología de la Nación, que fue reconocido por la Ley de Educación 26.206 en 2006, con una programación cultural de excelente factura técnica y estética. El canal infantil Paka-Paka salió al aire en 2010 luego de haber sido la franja infantil de la programación del canal Encuentro. A partir de la instalación del sistema de televisión digital abierta en 2010, se crearon nuevos canales estatales digitales como Tecnópolis TV, INCAA TV y DeporTV. Además, desde 2005 se había incrementado el presupuesto de los medios preexistentes -Canal 7 y Radio Nacional-, se instalaron nuevas antenas repetidoras con el objeto de ampliar su cobertura, se modificó la programación y se contrataron nuevos profesionales. Asimismo, desde 2007 se impulsaron las jornadas denominadas Encuentros de televisión pública para debatir sobre líneas de acción para los medios de gestión estatal y se creó el Consejo Federal de Televisión Pública. Desde 2010, en cumplimiento del artículo 89 de la Ley de Servicios de Comunicación Audiovisual, se autorizaron nuevas radios y canales de televisión abierta y por cable pertenecientes a entidades estatales: municipios, provincias, escuelas y universidades públicas, aunque la mayoría de ellos aún no comenzó a transmitir ${ }^{20}$.

En general, el mercado de medios de la Argentina es inestable y las empresas presentan una relativa fragilidad debido a la conjunción de diversos factores. El sistema audiovisual argentino tiene una "complicación objetiva: la debilidad de su estructura de mercado" (Becerra, 2009). De las cinco mil estaciones de radio que funcionan en el país, menos del 5\% se autofinancia con publicidad. Las empresas de televisión abierta, sector que absorbe el $36 \%$ de una torta publicitaria calculada en 7 mil millones de pesos anuales, afirman que no son rentables. Los canales líderes en audiencia son la excepción, con ganancias basadas en su amplia audiencia acumulada en sus redes de transmisión en horario central (prime time) y en la

\footnotetext{
$20 \quad$ La cantidad de licencias autorizadas a entes estatales después de la sanción de la LSCA es motivo de controversia (Crettaz, 2013; Krakowiak, 2013) y no está disponible públicamente.
} 
exportación de contenidos. "La televisión por cable es redituable, pero su mercado [...] es cautivo del proveedor dominante". Por eso, los empresarios del sector objetaron el ingreso de nuevos actores sociales y públicos al mapa de los medios. De todos modos, "la cuestión económica" incluye también la sustentabilidad de los medios de gestión social y estatal (Becerra, 2009).

Además, la convergencia de los medios (telefonía, televisión por cable e internet) sitúa a las empresas mediáticas en una situación de "creciente fragilidad" (Sorj, 2010, p. 10) en tanto atrae el interés de poderosos agentes económicos al área de la producción de contenidos; particularmente a las grandes empresas de comunicación y los grandes portales de internet que "en general son empresas económicamente más poderosas que los grupos tradicionales del área de comunicación" (Ibíd., p. 12) y corren con ventajas para la prestación de servicios convergentes. Efectivamente, "la telefonía es el sector de las comunicaciones que más creció" y hoy en la Argentina "el principal negocio no es la usina sino la distribución electrónica del cable" (Edi Zunino, citado por Ludueña, 2010, p. 273). No casualmente, durante el debate de propuestas de la nueva ley de radiodifusión, la operación de compra y venta que concitó mayor atención por parte de las empresas mediáticas fue la entrada el 7 de mayo de 2008 de Telefónica en Telecom con el consiguiente riesgo de constitución de un monopolio en el sector de telefonía en el país ${ }^{21}$.

\section{Las tomas de posición}

Conceptualizar las prácticas discursivas como resultado de opciones - que se objetivan en un texto- realizadas por un agente social en función del lugar que ocupa en un sistema de relaciones implica postular un comportamiento estratégico, aun cuando no sea necesariamente consciente ni racional (Mozejko \& Costa, 2007) 22 . La producción discursiva está orientada a influir sobre otros (Charaudeau, 2003 , p. 50-51). El agente productor prevé que su discurso es susceptible de responder a una contrainfluencia de la que tampoco es necesariamente consciente.

21 Esto, sumado al trascendido de que el proyecto gubernamental de nueva ley permitiría a las telefónicas la prestación de servicios de radiodifusión (como de hecho ya estaba sucediendo con Telefé), incrementó el temor por el ingreso de las telefónicas al negocio de las comunicaciones. "La discusión sobre la Ley de Servicios Audiovisuales llevaba como plataforma semioculta la disputa con las telefónicas” (Entrevista de María Eugenia Ludueña a Martín Becerra [Ludueña, 2010, p. 273]; Mastrini, 2010, p. 114-124). En efecto, el proyecto de ley formulado por el PEN permitía a las empresas de telefonía el ingreso al sector, lo que hubiera implicado una importante competencia para los grupos mediáticos. Sin embargo, esto luego fue dejado de lado y quedó pendiente la necesaria regulación del triple play.

22 Esto remite al problema de la intencionalidad. Con este concepto hacemos referencia a una orientación de la acción que se infiere del espacio de posibilidades - objetivo y percibido- en el que actúa el agente social. 
Asimismo, todo enunciado es siempre una respuesta a enunciados anteriores (con los que confronta o junto con los que se inscribe en determinada tradición). De este modo, el discurso tiene siempre una dimensión polémica. La estrategia de abordaje de los textos adoptada a los fines de identificar y poner de manifiesto las opciones realizadas por el agente y objetivadas en ellos es la construcción del enunciador en cuanto simulacro textual, que se perfila sobre la base de relaciones con los demás elementos del enunciado, descriptibles a partir de datos textuales: enunciatario, otros enunciadores, enunciado e instituciones (Mozejko \& Costa, 2002, p. 43).

En esta sección se analizarán cuáles son las características específicas de las prácticas discursivas producidas por las entidades que nuclean a televisoras y productoras audiovisuales sin fines de lucro de la Argentina a partir de la entrada en vigencia de la Ley 26.522.

Como las organizaciones estudiadas produjeron pocos documentos propios hasta el momento, el corpus de análisis está compuesto por libros realizados por las entidades que impulsaron su constitución -COPLA (2011), que desarrolló FECOOP-TV, y la Usina de Medios (Mirad et al., 2012), que apoyó la creación de Trama Audiovisual - o por sus referentes; en el caso de Espacio Abierto de Televisoras Populares, Alternativas y Comunitarias, se analizó el libro compilado por Natalia Vinelli (2011), referente a esta entidad.

\subsection{Seducción y rechazo}

Al tratarse de producciones realizadas por referentes de asociaciones recientemente conformadas y en pleno proceso de inclusión de nuevos miembros, de desarrollo y de presentación pública, los tres textos analizados detallan estas propuestas de organización y procuran captar potenciales adherentes. Con esa orientación, los agentes productores de los discursos analizados construyen un lugar desde donde hablar y a partir del cual buscan legitimarse, así como volver aceptables y verosímiles sus enunciados y captar a sus enunciatarios.

Configuran como enunciatarios privilegiados a otros canales o productoras audiovisuales sin fines de lucro de su mismo tipo que puedan sumarse a la propuesta de integración en una entidad de segundo o tercer grado. Aunque los tres organismos apuestan a la construcción colectiva, difieren en el tipo de entidades a las que invitan a sumarse: canales cooperativos y mutuales en el caso de Trama Audiovisual; televisoras y productoras audiovisuales ligadas a movimientos terri- 
toriales y fábricas recuperadas por sus trabajadores en el del Espacio Abierto de Televisoras Populares, Alternativas y Comunitarias; y productoras y asociaciones de trabajadores del sector audiovisual de tipo cooperativo, sindical y/o pyme, tal como es el caso de FECOOP-TV. En particular, con respecto a la participación de los medios pyme, se registran variaciones en los tres discursos:

- En la construcción de FECOOP-TV "también pueden participar los pequeños empresarios del sector privado" (COPLA, 2011, p. 102). Por eso, FECOOP-TV pone el acento en la construcción federal en oposición a las grandes corporaciones mediáticas y apuesta a una "articulación política, económica, social y cultural" para dar cuenta de la heterogeneidad de sus integrantes. FECOOP-TV justifica la inclusión de ciertos medios con fines de lucro por la necesaria unión de los débiles -tengan o no fines lucrativos - frente a las corporaciones mediáticas.

- En cambio, a pesar de que objetivamente un tercio de sus integrantes son también pequeñas empresas, Trama pone el acento en la "comunidad organizada" ("[El convite] debe sobrepasar la barrera de las cooperativas y mutuales para hacerse extensivo a clubes, asociaciones vecinales, ONG y demás instituciones sin fines de lucro" (Berlanga, 2012, p. 206), con "arraigo territorial" e "inserción social". De este modo, se refiere al sector social sin fines de lucro de origen comunitario, por oposición al sector privado con fines de lucro y a diferencia del Estado y del sector social sin fines de lucro, pero cuyo origen no se encuentra en la comunidad organizada como las fundaciones empresarias. Así, invisibiliza la participación de canales con fines de lucro.

- En cambio, en el Espacio Abierto, se diferencian claramente de los medios pyme. Si bien coinciden con FECOOP-TV en caracterizarlos como aportes "a la desmonopolización y a la democratización de la comunicación" y en situación de "desigualdad frente a las grandes empresas", se sostiene, sin embargo, que al tener fines de lucro, "los medios populares compiten en desigualdad de condiciones" con ellos (Vinelli, 2011, p. 29).

Se reconoce que las competencias cognitivas y pragmáticas de los destinatarios a quienes se invita a participar no serán homogéneas, pero se constituye a todos como competentes de algún modo, lo que aportará a la construcción colectiva:

Ahora bien, no cualquier entidad sin fines de lucro puede hacerse cargo de un canal de televisión. Pero sí todas pueden formar parte del mismo. Participar en el proceso. Aportar saberes. De gestión, de comercialización, de financiamiento. Aportar capital. Trabajo. Construir solos o en colaboración, mensajes audiovisuales periódicamente (Berlanga, 2012, p. 206). 
En estas competencias sociales, económicas y profesionales de sus asociadas actuales (y futuras), Trama sustenta su poder y su poder hacer:

Se trata de canales de TV construidos por instituciones con fuerte arraigo territorial. Con solvencia económica y experiencia en gestión. Con periodistas, comunicadores, diseñadores, realizadores y artistas construyendo mensajes para su propia comunidad, pero también para el resto del país. [...] Sumando ahora sí, todas las potencialidades que le brindará a los canales de TV asociarse a Trama... (Berlanga, 2012, p. 214).

Las operaciones de construcción de los enunciatarios son diferentes en cuanto: - Trama apunta a un paradestinatario ${ }^{23}$ más amplio propio de la comunicación política que busca adhesiones, mientras que el Espacio define claramente al prodestinatario ${ }^{24} \mathrm{y}$ al contradestinatario ${ }^{25}$ (Verón, 1987). En el texto sobre Trama Audiovisual se identifica al enunciador con los trabajadores, especialmente de sectores medios y con las organizaciones sociales ("somos el colectivo social. Los trabajadores, profesionales, pymes, cooperativas, mutuales, sindicatos, organizaciones territoriales, civiles, escolares, artísticas" (Salerni, 2012, p. 20), en oposición a "la gente común de y en la actual gran pantalla". De este modo, plantea su legitimación para hablar en términos de: “...no [somos] intérpretes de lo popular sino, por el contrario, de los hacedores de la vida popular misma” (Ibíd., p. 21). Como estrategia para legitimar al enunciador y captar al enunciatario, se identifica la

\footnotetext{
23 En un contexto democrático, el discurso político tiene, además de un destinatario positivo y uno negativo, un tercer tipo de destinatario: sectores que se mantienen en cierto modo fuera del juego, a quienes es necesario persuadir (Verón, 1980, p. 93). La relación con él se basa en una suspensión de la creencia. Es un destinatario susceptible de escuchar y comprender. Con el paradestinatario habitualmente se asocian entidades enumerables que designan a organismos más amplios que los colectivos de identificación y que el enunciador político coloca habitualmente en posición de recepción, tales como: ciudadanos, argentinos, gente, etc. (Verón, 1987, p. 17-18). 24 Para Verón (1980, p. 93-97), el discurso político se organiza, por un lado, alrededor del colectivo de identificación que constituye el fundamento discursivo de los procesos de identificación propios de cada partido político o movimiento social. El prodestinatario es el destinatario positivo que se refuerza, ratifica y exalta. La relación con él se basa en una creencia presupuesta. Generalmente está asociado con un colectivo de identificación que se expresa en el nosotros inclusivo del enunciador y el prodestinatario.

25 El discurso producido alrededor del nosotros de identificación será recibido también por los adversarios, por los otros. Por eso, al tiempo que define la buena lectura, el discurso político está obligado a presuponer siempre la mala lectura, a suponer y anticipar una réplica. "El campo discursivo de lo político implica enfrentamiento, relación con un enemigo, lucha entre enunciadores" (Verón, 1987, p. 16), tiene necesariamente una dimensión polémica. El contradestinatario es el destinatario negativo que está excluido del colectivo de identificación, y la relación con él reposa en una inversión de la creencia. "Ese 'otro' discurso que habita todo discurso político es la presencia, siempre latente, de la lectura destructiva que define la posición del adversario". Es el destinatario imposible, sordo e impenetrable (Ibíd., p. 17).
} 
entidad con la sociedad misma ${ }^{26}$, en oposición a quienes solo la interpretan en los medios.

- En FECOOP-TV se apunta también a un paradestinatario amplio al que se identifica como "los ciudadanos", a quienes se caracteriza como privados de la posibilidad de ejercer la comunicación y quienes serían, por lo tanto, los principales beneficiarios de la acción que el enunciador propone llevar adelante. “...construir las instituciones $[\ldots]$ que permitan operar sobre la realidad $[\ldots]$ para $[\ldots]$ hacer visible [...] la vida de millones de ciudadanos que hoy no pueden comunicar ni recibir información" (COPLA, 2011, p. 101).

- En el Espacio Abierto, en cambio, se identifica con claridad al enunciatario con una clase social (el proletariado) en relación de enfrentamiento con otra (la burguesía). El enunciador depende de ese colectivo, aunque no lo constituye:

La televisión y los medios alternativos suponen [...] un periodismo dependiente, que toma partido por una clase social y vuelve esa posición evidente como forma de contrainformar sobre la pretensión de objetividad de los medios hegemónicos, que naturalizan la mirada de la burguesía como única y universal (Vinelli, 2011, p. 30-31).

\subsection{Valores y saberes}

Frente a esos destinatarios esperados, los agentes que producen los discursos buscan legitimar a los enunciadores al construirlos como competentes en términos axiológicos (saben lo que se debe hacer), cognitivos (saben) y pragmáticos (saben hacer). Los profusos componentes prescriptivos de los discursos de las tres entidades se refieren a dos grupos de valores: 1) el valor de la integración, la cooperación, lo común, lo colectivo, la participación, tanto como el valor del compromiso social, la inserción social y territorial, lo popular, axiologías que definen de modo privilegiado la identidad del sector social; y 2) el valor de dar la palabra y hacer visible, comunicar, dar a conocer, así como el valor de la calidad técnica y estética, axiologías relativas a la especificidad de la producción audiovisual.

Se trata de entidades que construyen su propia identidad basadas en el valor de la cooperación. Trama Audiovisual se define como colectivo social antes que por sus productos comunicacionales:

No es el producto mismo quien explica la comunicación. Las relaciones sociales y organizativas que lo anteceden son la condición de posibilidad del proceso de comu-

\footnotetext{
${ }_{26}$ Los metacolectivos singulares como "la sociedad" no admiten cuantificación y, difícilmente, la fragmentación porque son más abarcadores que los colectivos propiamente políticos que fundan la identidad de los enunciadores (Verón, 1987, p. 18).
} 
nicación y del producto mismo. Y es en esa construcción en la que estamos involucrados (Salerni, 2012, p. 21).

En sentido similar, FECOOP-TV hace alusión a la construcción de una organización con cierta distribución igualitaria del poder interno: "COPLA, desde su voluntad de articulación política, social, económica y cultural se asocia y busca el crecimiento de organizaciones plurales, sin hegemonismos" (COPLA, 2011, p. 102). El Espacio Abierto también destaca el valor de la colaboración y de lo colectivo pero en tanto condición de los medios que lo integran: “...la propiedad del medio es social y por lo tanto las decisiones sobre su vida y funcionamiento son colectivas" (Vinelli, 2011, p. 33-34).

A estas construcciones organizativas colectivas, cooperativas, participativas y colaborativas se les reconoce, no obstante, no solo un fundamento prescriptivo sino también uno pragmático: se las construye como condición de posibilidad de existencia y acción en el nuevo contexto. “...si nos federamos, nos fortalecemos y podemos" (COPLA, 2011, p. 103). "Unidos en una estrategia en común: potenciarse unos a otros" (Berlanga, 2012, p. 214).

De la misma manera que la colaboración es necesaria para poner al aire una programación televisiva [...], debería serlo [...] para ir resolviendo [...] temas que hacen al financiamiento y a la transferencia tecnológica. [...] estas dificultades deberían superarse de manera colectiva... (Vinelli, 2011, p. 28).

Este componente axiológico y pragmático se carga también de contenido pasional al dotar al valor de la cooperación de una valencia tal que lo hace equivalente a la supervivencia misma: “...hay una lección que el sector de la economía solidaria ya tiene aprendida: es imposible sobrevivir aislados, en la misma arena de quienes pelean por maximizar ganancias" (Berlanga, 2012, p. 205), "conscientes de la necesidad de agruparse para poder ser" (Ibíd., p. 212). Es, por lo tanto, la existencia misma de estos medios la que está en riesgo y las propuestas de articulación en una entidad mayor son alternativas verosímiles para evitarlo, "para emprender el futuro no ya como sueño sino ahora como posibilidad" (Salerni, 2012, p. 20), "construir un sistema empresarial que permita dotar de sustentabilidad el deseo de comunicar" (Berlanga, 2012, p. 205).

Estrechamente vinculado con los valores propios de la organización colectiva, está el de la inserción social y territorial.

...una de las principales fortalezas que deben tener en cuenta cada uno de los proyectos que se desarrollen. El arraigo territorial. La fortaleza social que implica la historia de una institución. La confianza que la comunidad tiene en su cooperativa o en su mutual (Berlanga, 2012, p. 206). 
Con los valores propios del sector (lo solidario, lo popular), se combinan valores específicos de la producción audiovisual (calidad técnica y estética). Así, por ejemplo, Trama sostiene: "Se trata de dotar de sustentabilidad a canales de televisión construidos con el fin montar una programación que fomente los valores solidarios, pero popular y de alta calidad" (Berlanga, 2012, p. 205).

Además de saber qué se debe hacer, los enunciadores se construyen como poseedores de dos tipos de competencias cognitivas y pragmáticas: 1) en tanto productores y distribuidores de comunicación audiovisual, pero también 2) como gestores, hacedores, organizadores capaces de construir y administrar instituciones (Trama Audiovisual y FECOOP-TV) y colectivos (Espacio Abierto) como las que están proponiendo.

Trama pone especial énfasis en construir sus competencias cognitivas y pragmáticas: sabe, sabe hacer y sabe hacer hacer a otros. Al definir un proyecto detallado de gestión institucional y económica, de organización de la producción, de la programación y contenidos, muestra que tiene experiencia en la formulación de proyectos y en la gestión. De este modo, se orienta a volver verosímil y aceptable su propuesta y así convencer a sus enunciatarios. En cambio, FECOOP-TV y Espacio Abierto ponen mayor énfasis en la construcción de un punto de vista axiológico. En cierto sentido, incluso, Espacio Abierto cuestiona la posibilidad de formular proyectos detallados en el ámbito de la comunicación alternativa: "No hay una receta para hacer televisión popular que no sea el ensayo y el error. La televisión y los medios alternativos suponen un espacio donde otro periodismo se construye y se pone a prueba todo el tiempo" (Vinelli, 2011, p. 30-31).

Los tres enunciadores se inscriben en ciertas genealogías al recuperar y mostrar las semejanzas de sus propuestas con las de otros enunciadores. El Espacio Abierto recupera la tradición del periodismo militante latinoamericano y de DOCA (Documentalistas de Argentina) por trabajar en articulación. También destaca las experiencias de organizaciones piqueteras y de empresas recuperadas por sus trabajadores en la Argentina y de medios comunitarios de Venezuela de aceptar financiamiento estatal y reconvertirlo en prácticas organizativas. Esta última cuestión se inserta en el debate que mantienen los medios del sector social-comunitario y, en especial, aquellos que adscriben a posicionamientos políticos de izquierda sobre la relación que deben y pueden mantener con el Estado.

FECOOP-TV y Trama Audiovisual, en sus propuestas de gestión institucional, se inscriben en una doble genealogía de modo tal que recuperan y compati- 
bilizan tanto las experiencias del sector social al que pertenecen - de organizaciones sociales, de cooperativas locales y de la Coalición por una Radiodifusión Democrática-, como las del gobierno que algunos de sus referentes integran y al que adhieren: las de nuevos organismos estatales participativos de políticas de comunicación como el Consejo Federal de Televisión Pública, el Consejo del Sistema Argentino de Televisión Digital Terrestre, el Plan INCAA de Fomento a las producciones locales (COPLA, 2011, p. 102 y Berlanga, 2012, p. 207-209).

Además, polemizan con otros enunciadores del sector empresarial de los que buscan diferenciarse y distanciarse. Todos coinciden en situarse en oposición a los "medios hegemónicos" (Vinelli, 2011), "la gran pantalla" (Salerni, 2012), "los monopolios [de medios]" (COPLA, 2011). "La alternatividad no se basa en la explotación del trabajo y la propiedad del medio es social y por lo tanto las decisiones sobre su vida y funcionamiento son colectivas" (Vinelli, 2011, p. 33-34).

Pero sí es necesario abandonar rápidamente la lógica de quienes montan medios para obtener ganancias. Se debe partir de un razonamiento diametralmente opuesto: construir un sistema empresarial que permita dotar de sustentabilidad al deseo de comunicar (Berlanga, 2012, p. 205).

Surgen diferencias entre los tres discursos en la definición de otros enunciadores del sector social, de los que buscan diferenciarse. Esta estrategia es particularmente notable en el caso de Espacio. Construye su punto de vista valorativo y cognitivo al tomar distancia de otros enunciadores de medios sin fines de lucro de modo más o menos explícito:

Las televisoras que priorizaron lógicas de organización y gestión microempresarias [...] (lógica comercial), [...] aquellas que se plantearon como alternativas y comunitarias [...] (lógica de transformación) [...] las prácticas televisivas que buscaron hacer lo suyo en un marco [...] de vinculación con caudillos y funcionarios municipales como estrategia de supervivencia [...] (lógica de cooptación $)^{27}$ (Vinelli, 2011, p. 18-19).

Espacio Abierto también hace alusión a otros enunciadores de manera implícita al construir como enunciatarios a quienes conocen el sistema de relaciones específico de los medios no lucrativos y pueden comprender a quiénes se está haciendo referencia. De este modo, se distancia de quienes postulan la necesidad de salir "a jugar en cancha grande" (en referencia a reemplazar las prácticas artesanales y marginales, como si tal cosa dependiera solo de la voluntad de los medios sociocomunitarios) y de quienes incluyen a las pymes en el sector (como FECOOP-TV y

27 Frases entre paréntesis en el original. 
Trama Audiovisual). Se diferencia también de la asepsia política de medios locales, pequeños y artesanales, y de medios alternativos que priorizan "tomar la palabra" antes que la masividad y hacer televisión antes que verla. Asimismo, precisa las distancias con medios alternativos ligados a organizaciones revolucionarias y con medios orgánicos de organizaciones partidarias porque sostiene que la prensa alternativa contiene a la prensa partidaria.

\subsection{Del repliegue a la acción}

En esta línea, comienzan construyendo un programa narrativo ${ }^{28}$ de la privación, la carencia y la resistencia en una larga historia en la que el sector sin fines de lucro habría surgido, se habría desarrollado y mantenido en la invisibilidad, la ilegalidad y hasta la persecución, trasvistiéndose en formas legales, buscando modos de sobrevivir solos o de modo colaborativo junto con otros, resistiendo la indiferencia y hasta la criminalización por parte del Estado, así como la competencia desleal y presiones de las empresas privadas de medios. Trama Audiovisual lo caracteriza así:

Hemos vivido en el anonimato mediático y de la institucionalidad formalista de los gobiernos durante mucho, muchísimo tiempo. Aun como beneficiarios, como los que necesitan alguna ayuda especial y reconocimiento para vivir lo más parecido posible a la normalidad (Salerni, 2012, p. 20).

Luego proponen un segundo programa narrativo de la transformación, en el que estas entidades se configuran como agentes del cambio del que serán las principales beneficiarias. Ante la oportunidad que abre la sanción de la Ley de Servicios de Comunicación Audiovisual, el modo de lograr el cambio es potenciarse, sumar fuerzas, construir poder por medio de la integración. De este modo y en cooperación con otros agentes a los que se configura como aliados - otras organizaciones sociales (Espacio Abierto de Televisoras Populares, Alternativas y Comunitarias), pymes y asociaciones sindicales (FECOOP-TV) y otras cooperativas (Trama Audiovisual)_, podrán salvar su principal obstáculo (la falta de recursos económicos) y enfrentarse en mejores condiciones a los agentes a los que todos

\footnotetext{
28 De acuerdo con Charaudeau (1982), en el aparato formal narrativo, ante la identificación de una carencia se desarrolla una búsqueda que es llevada a cabo por el agente de la búsqueda, para lograr conseguir el objeto que representa la carencia colmada. Esa búsqueda tiene cierto resultado positivo o negativo. En la narración se identifican los siguientes actantes: agente, beneficiario, aliado, oponente (humanos), paciente, auxiliar, obstáculo (no humanos) [las cursivas son nuestras].
} 
construyen como oponentes (los medios hegemónicos) o presionar al Estado para obtener mejoras.

FECOOP-TV destaca la oportunidad - "[U]no de los desafíos más importantes que dejó la sanción de la Ley de Servicios de Comunicación Audiovisual es el de construir instituciones o las articulaciones..." (COPLA, 2011, p. 101-102)—, identifica a sus oponentes a los que sobrecarga de valor negativo - "luchar contra los monopolios, esos que gobiernan a escala nacional y que se reproducen ilimitadamente en cada ciudad importante o capital de provincia"29- y el modo en que va a actuar - "es fundamental crear empresas que no existían previamente a la sanción de la Ley. [...] para poner la Ley en vigencia es necesario construir organización" (Loc. cit.).

Trama coincide en identificar la oportunidad — "[La p]osibilidad [de que las entidades sin fines de lucro formen parte de la comunicación audiovisual] que hasta la sanción de la nueva ley de Servicios Audiovisuales les estaba expresamente prohibida..." (Berlanga, 2012, p. 205) —; el modo asociativo en que va a actuar; su interés - “...cooperativas, mutuales, gremios y otras entidades sin fines de lucro desean formar parte del mundo de la comunicación audiovisual" (Loc. cit.)—; y el necesario paso de la pasividad a la acción: “...dejamos el ejercicio de la crítica del discurso y pusimos el tiempo en perfeccionar nuestras herramientas y en desarrollarlas..." (Salerni, 2012, p. 20).

Para Espacio Abierto, la comunicación es un instrumento de luchas políticas, aun cuando requiere de conocimientos específicos. Define así un objetivo de la acción: "Montar un canal es sumamente importante dentro de una estrategia emancipadora, sobre todo teniendo en cuenta el papel hegemónico que la televisión viene cumpliendo...” (Vinelli, 2011, p. 20). “...Que la televisión sea parte de un proyecto alternativo a secas, pero que también sea televisión y requiera un modo de funcionamiento y $[\ldots]$ un tipo de militancia que reconozca esa especificidad" 30 (Ibíd., p. 13). De allí que el objetivo de la acción sea "la masividad, es decir, la visibilización y por lo tanto la disputa de sentido” (Ibíd., p. 12). Para alcanzarlo, la acción del agente se encuentra con obstáculos tecnológicos y de modalidad de trabajo - “...unas prácticas artesanas por un lado, y por otro con las limitaciones propias de una tecnología de desecho (la televisión de aire) que achica la llegada de manera considerable" (Ibíd., p. 12) - y estructurales: “...al desarrollarse en

\footnotetext{
29 Las cursivas son nuestras.

30 Cursivas en el original.
} 
el marco de una formación social capitalista, estas experiencias estarán todo el tiempo tensionadas entre la transformación y la reproducción de la cultura y la comunicación hegemónicas" (Ibíd., p. 16). Frente a esto, por un lado, los agentes configurados como aliados se construyen también como condición de posibilidad de la acción: “...estas dificultades deberían superarse de manera colectiva, gestionando relaciones con los procesos populares del continente, compartiendo tecnología y proyectos presentados, poniendo en común vías de financiamiento" (Ibíd., p. 28). Además, por otro lado, resemantizan la restricción de sus modalidades de trabajo como oportunidad: “...las determinaciones que hacen a la televisión alternativa, $[\ldots]$ aunque no garanticen un funcionamiento alternativo en todos los casos, necesariamente generan un punto de partida (un modelo de comunicación) que es radicalmente diferente al de los medios hegemónicos y las corporaciones multimediáticas" (Ibíd., p. 11).

En general, los componentes programáticos que construyen las tres entidades pueden agruparse en tres ejes centrales: la gestión institucional y económica, la producción temática y estética y el vínculo con el Estado. No obstante coincidir en estas bases, las principales diferencias surgen en las tomas de posición de los agentes.

Con respecto a la gestión institucional, COPLA (Comunicación y Política en el Proyecto Nacional), organización que impulsó la creación de FECOOP-TV, sostiene que "para poner la ley en vigencia es necesario construir organización", "crear empresas que no existían previamente a la sanción de la ley" (COPLA, 2011, p. 102). En el mismo sentido, Usina de Medios, entidad mixta entre el gobierno nacional y las cooperativas, que impulsó la constitución de Trama Audiovisual, sostiene que canales de baja potencia, señales locales de cableoperadores y proyectos de canales de Televisión Digital Abierta construyeron Trama como una herramienta para poder "competir dentro y fuera de la pantalla de los televisores" (Ibíd., p. 212): coproducir contenidos, reducir costos y obtener escala nacional al comercializar las pantallas (Ibíd., p. 212-213).

Espacio Abierto propone la construcción de una entidad de segundo o tercer grado que reúna a televisoras y productoras alternativas, pero no con el objetivo de producir en conjunto, sino de demandar al Estado mejores condiciones para el sector.

Sobre la producción temática y estética, FECOOP-TV y Trama Audiovisual ponen énfasis en la producción en red de contenidos locales. Trama, además, 
busca fomentar valores ligados al cooperativismo. Por su parte, FECOOP-TV y Espacio destacan la posibilidad de decir lo que los medios dominantes no dicen o visibilizar lo que invisibilizan (COPLA, 2011, p. 101-102 y Berlanga, 2012, p. 205):

...no se trata solamente de "dar vuelta la información oficial", sino de la necesidad de construir una agenda propia que se proponga disputar el sentido común dominante $\mathrm{o}$, al menos, que ayude a instalar nuevas preguntas [...] esto también hace a las condiciones de producción del medio. Las fuentes son antes que nada los propios sectores movilizados, con los que comparten las luchas y cuyas exigencias se difunden en primer lugar. El análisis arranca con las causas, de manera de poder denunciar las consecuencias y las maneras de frenarlas atacando justamente las causas que las originan (Vinelli, 2011, p. 30-31).

Todas ponen énfasis en la importancia de su inserción local, social y territorial para producir una agenda y una estética propias. FECOOP-TV pone de relieve la posibilidad que su particular constitución le otorga de producir contenidos de carácter federal. Trama Audiovisual destaca la inserción social y territorial de las cooperativas y mutuales que la conforman como aspecto que los diferencia de los medios del sector privado-comercial y del público-estatal. Considera que la posibilidad de construir una propuesta propia, diferente de la de los medios hegemónicos, se basa en las características que asuman las relaciones sociales de sus productores.

¿Cómo se puede construir una programación competitiva, popular, masiva, atractiva con bajos costos? La única respuesta posible la debemos encontrar en dos pilares fundamentales: el modo de construir la programación local y en la fortaleza que pueda otorgarle el asociativismo y la coproducción (Berlanga, 2012, p. 210).

Espacio Abierto también pone de relieve su vínculo con organizaciones populares y las condiciones de su propia organización como facilitadores para producir una comunicación no hegemónica.

Estas condiciones de producción [la cooperación, colaboración y solidaridad], que son opuestas a las del sistema mediático hegemónico, son la argamasa sobre la que crece otra comunicación, pero no configuran una vacuna por sí mismas ni garantizan per se la alternatividad. Lo que sí favorecen [...] es el desarrollo de unas relaciones proclives al cambio que la competencia como punto de partida nunca puede generar (Vinelli, 2011, p. 15-16).

...el lugar que ocupa la TV popular entre los sectores movilizados de la sociedad, y las maneras en que se tejen relaciones que generan una confianza muy diferente de la propinada hacia los medios hegemónicos (lo cual redunda en un tipo de cobertura periodística sensiblemente distinta) (Ibíd., p. 17-18).

No obstante, reconocen las dificultades de producir con una estética diferente de los modelos tradicionales cuando sus productores han sido formados y se 
han socializado como públicos de los medios masivos de comunicación en los que predomina históricamente la lógica comercial. Frente a este problema, en Espacio problematizan los formatos masivos, mientras que en Trama Audiovisual consideran que es posible usar los formatos que la audiencia masiva está acostumbrada a consumir con contenidos diferentes que reflejen los valores del sector social y cooperativo y, en particular, la ideología de cada canal (Kirzner, 2013):

...podemos observar las estrategias enunciativas y de estilo elegidas para la conducción, que tienden por momentos a repetir esquemas aprehendidos como televidentes desde nuestra infancia, o la organización de los programas a veces con criterios no muy distintos de los que la TV tradicional nos tiene a esta altura acostumbrados para el segmento de público joven (Vinelli, 2011, p. 17-18).

Finalmente, acerca del vínculo con el Estado también se registran diferencias entre Trama, FECOOP-TV y Espacio. Según se mostró más arriba, los primeros reivindican las instituciones participativas del Estado y las construyen como antecedentes de sus propias prácticas junto con las experiencias de ciertas organizaciones sociales (Berlanga, 2012, p. 309 y COPLA, 2011, p. 102). FECOOP-TV va más allá: construye al gobierno a cargo del Estado y al partido gobernante como sus aliados. Destaca el papel que "Néstor y Cristina" y "la presidenta" tuvieron en el impulso dado al enfrentamiento con los medios hegemónicos (opositores) y a la nueva ley de radiodifusión, respectivamente (COPLA, 2011, p. 101). En cambio, Espacio discute el vínculo que los medios sin ánimo de lucro deben y pueden mantener con el Estado. Explicita que las nuevas condiciones abiertas por la "ley de medios" "reactualizan estas históricas polémicas" sobre los niveles de autonomía posibles (Vinelli, 2011, p. 24). En estos debates que "encienden las posturas más radicalizadas", Espacio toma una posición intermedia:

[...] la tensión no se genera en la institución que financia al medio [...] sino en los efectos que este financiamiento tenga finalmente en la práctica, cuestión que debe resolverse en el seno de la misma. [...] Puede suceder que ante la presión el medio responda con una intervención política organizada, con la movilización de los sectores del campo popular que apuestan a su crecimiento y con la denuncia de chantaje que este tipo de amenazas genera. Lo estratégico en este plano [...] está dado por la inserción de la televisión en un proyecto mayor, capaz de intervenir en los conflictos que el desarrollo normal de cualquier práctica social enfrenta (Ibíd., p. 25). 


\section{Las posiciones de poder relativo}

Desde la perspectiva de análisis propuesta, para comprender y explicar las tomas de posición analizadas, es necesario construir el lugar ${ }^{31}$ que los agentes que las producen ocupan en el sistema de relaciones. Es el principio que define la identidad social del sujeto ${ }^{32}$ a partir de "aquellas propiedades que, por ser socialmente valoradas, tanto positiva como negativamente, le dan existencia social, lo hacen visible, reconocible, acreditable y constituyen la fuente de su capacidad diferenciada de relación (poder)" (Costa \& Mozejko, 2009). Define, así, la competencia relativa del agente en tanto capacidad diferenciada de relación, "probabilidad de ser aceptado y/o imponerse" (Costa \& Mozejko, 2001b, p. 47). Este poder se basa en el control diferenciado de propiedades y recursos eficientes, en el uso y gestión que el agente haga de esos recursos (Ibíd., p. 51) y en su trayectoria en tanto "proceso de acceso y/o adquisición, no necesariamente creciente y lineal, de propiedades y recursos en grado, volumen y estructura" (Ibíd., p. 50) ${ }^{33}$.

Se abordarán aquí las propiedades eficientes generadoras de diferencias que controla cada uno de estos agentes colectivos, sus trayectorias y estrategias de gestión.

\subsection{Recursos, trayectorias y gestión}

En lo que atañe a la gestión institucional, la mayoría de los medios y productoras audiovisuales del sector social están desarrollando alianzas estratégicas para acumular mayor control de recursos y poder relativo frente al Estado y a las empresas mediáticas. Así, a partir de la entrada en vigencia de la Ley de Servicios de Comunicación Audiovisual, muchas de estas organizaciones sin fines de lucro conformaron entidades de segundo y tercer grado a nivel nacional. Con diferentes objetivos, se produjeron: la Federación Cooperativa de Productores de Contenidos Audiovisuales (FECOOP-TV), Trama Audiovisual y Espacio Abierto de Televisoras Alternativas, Populares y Comunitarias.

FECOOP-TV reúne a unas 70 organizaciones cooperativas, gremiales y pymes de producción audiovisual: Asociación Argentina de Televisoras PYME y co-

\footnotetext{
31 Costa y Mozejko conceptualizan como "lugar" el principio de construcción social del agente a partir de las propiedades socialmente eficientes en tanto valoradas.

32 Ninguna de estas categorías implica una dimensión psicológica. La identidad del agente es lo que es socialmente.

33 La noción de "trayectoria" no debe confundirse con "biografía". No se refiere al sujeto empírico ni al sujeto "biográfico" (Costa y Mozejko, 2001b, p. 45; Bourdieu, 1997, p. 82).
} 
munitarias (AATECo), Cooperativa de Provisión y Comercialización de Servicios Comunitarios de Radiodifusión (COLSECOR), Federación de Cooperativas Telefónicas del Sur Limitada (FeCoSur), Diarios y Periódicos Regionales de la Argentina (DyPRA), Instituto Movilizador de Fondos Cooperativos (IMFC), Unión y Federación Argentina de Músicos Independientes (UMI/FAMI), Guionistas organizados, Pueblos Originarios representados en la Autoridad Federal de Servicios de Comunicación Audiovisual (AFSCA) y Directores de Obras Audiovisuales para Televisión (DOAT) (Piccone, 2011). FECOOP-TV se constituyó el 3 de abril de 2011 para producir e intercambiar contenidos audiovisuales -incluso publicitarios-, desarrollar formatos, gestionar recursos - entre ellos, pautas nacionales-, acceder a la tecnología digital, acceder al Sistema Argentino de Televisión Digital Terrestre (SATVD-T), contar con equipamiento e infraestructura de producción, capacitar a sus profesionales. FECOOP-TV fue impulsada por COPLA (Comunicación y Política en el Proyecto Nacional).

Por su parte, Trama Audiovisual es una cooperativa integrada por 39 canales: 13 de baja potencia asociados a AATECO, 13 señales locales de cableoperadores pertenecientes a cooperativas eléctricas y 13 proyectos de canales de televisión digital abierta sin fines de lucro pertenecientes a cooperativas, mutuales, pymes y sindicatos de localidades de las provincias de Córdoba, Buenos Aires, Santa Fe, Chaco, Tucumán, Neuquén y La Pampa ${ }^{34}$. Trama Audiovisual se lanzó el 25 de octubre de 2012 impulsada por Usina de Medios, organismo mixto formado por la Confederación Cooperativa de la República Argentina (Cooperar) que desde 1962 nuclea a las federaciones de cooperativas de consumo, crédito, consumo, seguro, viviendas, eléctricas y farmacéuticas, y por el Instituto Nacional de Economía Solidaria (INAES), ente autárquico del Ministerio de Desarrollo Social de la Nación. Trama tiene personería jurídica. Los 39 canales se asociaron para coproducir contenidos, reducir costos y obtener escala nacional al comercializar

\footnotetext{
34 Canal 11, TV Cooperativa de Servicios Villa Huidobro Ltda., Córdoba; Canal local, Medios SYMS Producciones, Zárate, Buenos Aires; Canal 9 "PROA Centro", Asociación Civil TV Abierta y Gratuita, Oeste serrano, Córdoba; Centro Cultural de la Cooperación, Instituto Movilizador de Fondos Cooperativos, Buenos Aires; Coopamuco (Cooperativa Padre Mujica de Comunicación), Villa 31, Buenos Aires; Canal 4 Cooperativa "Martín Casteluci" (ComarcaSI), Martínez, Buenos Aires; Canal 9 La Costa, San Bernardo, Buenos Aires; Cooperativa Sudecor Litoral Ltda., Bell Ville, Córdoba; Cooperativa Eléctrica de Obras y Servicios Públicos de Oncativo Ltda., Córdoba; Pulso TV, Femucor, Córdoba; Cooperativa de Servicios Públicos, Morteros, Córdoba; Amucha Fe TDA, Resistencia, Chaco; Colsecor TV Cooperativa, Córdoba; Río TV, Federación Santafesina de Entidades Mutuales Brigadier López, Santa Fe; Lanús TV, Buenos Aires; TV Cooperativa Canal 13, Cooperativa de Energía Eléctrica de Zapala, Neuquén; Cooperativa de Trabajo Palermo Viejo TV, Buenos Aires; AMPSSA, San Nicolás, Buenos Aires; Asociación de Prensa de Tucumán; Cooperativa Popular de Electricidad, Obras y Servicios Públicos de Santa Rosa Ltda., La Pampa; Celta TV, Tres Arroyos, Buenos Aires (Centro Cultural de la Cooperación, 2012).
} 
las pantallas (Berlanga, 2012, p. 212-213). Mientras consigue autogestionarse, está respaldada económicamente por Cooperar (Berlanga, 2013).

En tanto, Espacio Abierto de Televisoras Populares, Alternativas y Comunitarias nuclea a ocho televisoras: Barricada TV (vinculada con la fábrica IMPA recuperada por sus trabajadores), Faro TV (ahora dividido en el Canal 5 Comunitario y Faro TV), Canal 4 Darío y Maxi (ligado al Centro Cultural Manuel Suárez), TV PTS (orgánica del Partido de los Trabajadores Socialistas, PTS), En Movimiento TV (ahora, Dignidad TV, orgánica de Libres del Sur), Pachamérica TV Canal 5 de Jujuy (uno de los dos canales del interior del país perteneciente al movimiento que dirige Carlos "El Perro" Santillán), Gen TV (de Organizaciones Libres del Pueblo e integrante de la Red Nacional de Medios Alternativos, RNMA) y Mendoza Giramundo TV (el otro canal del interior del país también integrante de la RNMA); y a tres productoras audiovisuales: Cine Insurgente, Ojo Obrero (orgánica del Partido Obrero) y Silbando Bembas ${ }^{35}$ (Vinelli, 2013 y sitio web de Espacio Abierto de Televisoras Alternativas, Populares y Comunitarias [EATAPC] ${ }^{36}$ ). Espacio Abierto se constituyó en 2011 para manifestarse en protesta por las condiciones del llamado a licitación de nuevas licencias de televisión digital realizado por la AFSCA y exigir medidas de protección de su actividad. Su primera aparición pública fue en una protesta frente a la sede de la AFSCA en Buenos Aires el 23 de septiembre de ese año.

En cuanto a la gestión económica, estas organizaciones - a las que, como se observó, ahora se les reconocen derechos pero también obligaciones por cumplir en materia de producción de contenidos propios, infraestructura y funcionamiento- están repensando una política de financiamiento para esta nueva etapa ya que los montos a cubrir, incluso si los pliegos fueran gratis, son muy altos. Las opciones de financiación actualmente existentes son, entre otras: la cooperación internacional, publicidad oficial o privada, financiamiento directo e indirecto del Estado y/o asociarse entre diversas organizaciones en experiencias de "economía social" (Calicchio, 2011; Marino, 2011; Calicchio \& Vinelli, 2012). Por eso, al articularse en organismos de mayor grado, las entidades integrantes de FECOOP-TV y Trama Audiovisual apuestan a reducir costos por medio de la cooperación entre ellas y de obtener mejores ingresos al negociar articuladamente con las fuentes de financiación, entre ellas, el Estado.

\footnotetext{
35 Autores del documental "Hecha la ley... Un aporte al debate sobre los medios de comunicación" en 2011.

36 http://espacioabiertotv.blogspot.com.ar/
} 
Estas opciones de gestión institucional y económica dan cuenta de aprendizajes de lo necesario, lo útil, lo valioso y lo eficiente, realizados a lo largo de las trayectorias de las organizaciones y de los dirigentes que integran estas nuevas entidades. "Los niveles progresivos de acumulación logrados mediante el trabajo propio (gestión) dentro de los límites de lo posible van redefiniendo su identidad social, su competencia, y establecen nuevos horizontes, nuevas posibilidades de ser aceptado, escuchado, tenido en cuenta" (Costa \& Mozejko, 2009, p. 10-11).

En el sector de las cooperativas de comunicación, Trama Audiovisual y FECOOP-TV fueron precedidas por la constitución de DyPRA, la Federación Argentina de Diarios y Comunicadores Cooperativos de la República Argentina (FADICCRA) y COLSECOR, además de las experiencias de articulación del sector cooperativo en otros rubros de la actividad económica. Ambas entidades suman también la experiencia de asociacionismo de AATECO, que integra tanto a medios pymes con fines de lucro como a alternativos. Sus dirigentes reconocen haber aprendido mucho de ellas, en particular en lo referido a "cómo lograr que mucha gente de diversas realidades se ponga de acuerdo en un proyecto común”. Además, aprovecharon la acumulación de sus competencias: se conocían previamente, sabían integrar el trabajo de pymes con cooperativas, sabían trabajar con cooperativas locales y constituyen entidades de segundo grado (Berlanga, 2013). Además, ambas incluyen también a asociaciones sindicales.

Por su parte, los medios y productoras que integran Espacio Abierto tienen una trayectoria vinculada con las organizaciones piqueteras surgidas a mediados de la década del 90, las cooperativas de trabajadores que recuperaron empresas que fueron a la quiebra durante la crisis de 2001-2002, movimientos sociales territoriales y partidos de izquierda. Estas diferencias y similitudes en las competencias y trayectorias contribuyen también a comprender las diferencias y similitudes en las tomas de posición de cada entidad colectiva que se analizaron en el punto 2.

Asimismo, las propuestas de FECOOP-TV y Trama Audiovisual, al recuperar estrategias de economía social ${ }^{37}$, retoman las experiencias de comunicación del sector social en la Argentina a partir de 2001: "[L]as prácticas de algunos colectivos de comunicación surgidos en esta época adoptaron algunas de las particulares características de las prácticas de otras organizaciones sociales de ese período: auto-organización, horizontalidad, participación, asamblea y autonomía [...], incluso en la toma de decisiones y la gestión" (Segura, 2011, p. 157).

37 Sobre economía social en general, véase Coraggio, 2007. 
El poder relativo de las cooperativas de servicios públicos y los gremios que conforman FECOOP-TV y Trama Audiovisual es mayor que el de otros movimientos y organizaciones territoriales y estudiantiles que integran Espacio Abierto, en términos de fortaleza institucional (por su desarrollo y trayectoria), de recursos económicos y tecnológicos y de experiencia de gestión. En efecto, según referentes de Espacio, las cooperativas son las mejor posicionadas del sector social para ocupar el 33 por ciento del espectro reservado para los actores sin fines de lucro (Vinelli, 2013). Por lo tanto, si bien a nivel del sector social se registra la estrategia coincidente de aglutinarse en una entidad de mayor grado para incrementar su poder relativo en vistas a incidir en el Estado y asegurar su propia sostenibilidad, a nivel de los agentes colectivos se observa una diferencia en esta opción. Las dos entidades con mayor poder relativo realizan una propuesta de articulación destinada a producir, al plantear estrategias de colaboración con el Estado, mientras que la entidad con menor poder relativo propone una articulación orientada a la exigencia y demanda al Estado.

Las tres entidades cuentan con trabajadores con experiencia profesional en la producción de contenidos y la prestación de servicios de comunicación audiovisual. No obstante, Trama Audiovisual reforzó esta competencia al contratar un equipo profesional (director de contenidos, productora y guionista) con trayectorias exitosas en el sector privado-comercial. FECOOP-TV, por su parte, optó por incluir profesionales igualmente reconocidos provenientes del mismo sector de modo orgánico: los aglutinados en DOAT y Guionistas Organizados.

Con respecto a la relación con los medios del sector privado-comercial, si bien la Ley de Servicios de Comunicación Audiovisual establece relaciones de competencia por las audiencias y los recursos económicos, los vínculos que estas entidades mantienen con los medios lucrativos no son solo agonísticas. FECOOP-TV y Trama Audiovisual eligen integrarse con productoras audiovisuales y canales, respectivamente, de micro, pequeñas y medianas empresas. Esta opción plantea, sin embargo, dificultades de encuadramiento legal si se pretende acceder a financiamientos a la producción dirigidos específicamente al sector no lucrativo. Espacio Abierto, en cambio, elige la especificidad del sector no lucrativo y de la opción política, con televisoras y productoras ligadas - aunque no siempre de modo orgánico- a movimientos territoriales, fábricas recuperadas por sus trabajadores y partidos de izquierda. 


\subsection{Entre la autonomía y la cooptación}

Es particularmente relevante la variación que, según las posiciones de poder relativo, se producen en la gestión que las televisoras del sector social realizan con respecto al Estado, en tanto regulador y controlador del sistema de medios, y uno de sus principales financiadores ${ }^{38}$, además de uno de los tres tipos de operadores de medios. Si se considera que el área no lucrativa es la más débil de los tres sectores de la radiodifusión y que se ubica en relación de competencia con los actores lucrativos, necesita la cooperación del otro actor: el Estado ${ }^{39}$. Por eso, la opción por una relación de cooperación o disputa con el gobierno a cargo del Estado es otra de las principales estrategias adoptadas por los medios y productoras del sector social. La Ley de Servicios de Comunicación Audiovisual establece una relación de cooperación entre el Estado y los medios sin fines de lucro.

Todas las entidades del sector social, con estrategias de cooperación y/o confrontación, continúan reclamando que el Estado efectivice la asignación del 33\% del espectro radioeléctrico a las entidades sin fines de lucro y que contribuya a su sostenimiento económico. Así, algunas continúan ocupando activamente los espacios de participación en los organismos estatales que la Ley 26.522 ha abierto como el Consejo Federal de Servicios de Comunicación Audiovisual (COFECA)—, mientras que otras priorizan la movilización y manifestación en la calle.

Las más activas y frontales en el reclamo fueron las televisoras de Espacio Abierto. Durante 2011 y 2012 realizaron movilizaciones como el "Aguantazo cultural" frente a la sede de la AFSCA en octubre de 2011, publicaron artículos y documentos manifestando su postura —avalada por organizaciones sociales, políticas y sindicales, personalidades del mundo de la cultura y la defensa de los derechos humanos-, reuniones con las autoridades del área. Espacio también elaboró una propuesta de pliego que fue presentada a la AFSCA. En 2013, por ser un año electoral en el que los políticos tienen otras prioridades y es más difícil construir acuerdos, no se movilizaron (Vinelli, 2013).

\footnotetext{
38 No solo vía publicidad oficial, sino también con créditos, subsidios y exenciones impositivas, además de prórrogas de licencias, habilitaciones para desarrollar negocios, etc.

39 La relevancia de esta estrategia había quedado demostrada en el proceso de debate de las propuestas de la nueva ley de comunicación audiovisual. "Incluso la Coalición por una Radiodifusión Democrática, que formuló la propuesta de mayor radicalidad de las aquí analizadas y que estaba conformada por los agentes colectivos (instituciones) de mayor poder relativo dentro del sector social y por agentes individuales con prestigio y alta calificación, solo logró reconocimiento/visibilidad pública y, por lo tanto, capacidad de incidencia, cuando uno de los otros dos sectores más poderosos (el gobierno a cargo del Estado) la reconoció y convocó, a partir de lo cual, lo hizo también el otro sector (los medios masivos de gestión privada)" (Segura, 2011, p. 257 y 296).
} 
La Coalición por una Radiodifusión Democrática — de la cual varios integrantes de FECOOP-TV forman parte activa e integran su mesa directiva constituida en 2011-, hizo el reclamo pero de modo más suave y tardío. En una carta pública en marzo de 2012 sostuvo: "Los pliegos para los concursos de servicios regulados por la ley, vigentes y futuros, no deben contener exigencias administrativas, técnicas o económicas que signifiquen umbrales que excluyan a organizaciones populares o a pequeñas y micro empresas locales". Y reclamó "la puesta en marcha del Fondo Concursable de Promoción del 10\% del gravamen, con destino [a] los medios comunitarios, de frontera y de pueblos originarios" (Coalición por una Comunicación Democrática [CCD], 2012). En marzo de 2013, el plenario de la Coalición evaluó "la apremiante necesidad de formular el plan técnico que efectivice la reserva correspondiente a las organizaciones sin fines de lucro" (Coalición por una Comunicación Democrática, 2013). Finalmente, la Coalición acordó con la AFSCA y el COFECA la conformación de mesas de trabajo temáticas donde abordarían una agenda referida a los medios sin fines de lucro (Sabbatella, 2013, p. 8): la sostenibilidad de los medios sin fines de lucro, un plan técnico que ordene el espectro radioeléctrico con reserva del 33 por ciento del espectro radioeléctrico para el sector con participación de la CCD, la pronta legalización de las emisoras (radio y televisión) de baja potencia, un plan de capacitación y formación permanente, un nuevo modelo para la producción de contenidos audiovisuales y la fiscalización de los contenidos de programación y de emisoras repetidoras (Coalición por una Comunicación Democrática, 2013). Sin embargo, en "año electoral" no se esperan avances en la materia, salvo en la normalización del espectro, esto es: otorgar frecuencias en zonas no conflictivas y avanzar en resolver las situaciones conflictivas (Piccone, 2013).

FECOOP-TV y Trama Audiovisual mantienen una alianza con el gobierno que se hace visible con la presencia de funcionarios en su conducción y el apoyo de organismos estatales a su creación - en el caso de Trama Audiovisual, impulsada por la Usina de Medios- y a sus actividades, en el caso de FECOOP-TV y sus producciones, financiadas por el Sistema Argentino de Televisión Digital Terrestre (SATVD-T). En FECOOP-TV y Trama Audiovisual se hace evidente que los sujetos hacen uso estratégico de contar en su composición con funcionarios 
gubernamentales (quienes también son gremialistas o cooperativistas ${ }^{40}$ ), los que les permiten acceso diferenciado a recursos ${ }^{41}$. Por el contrario, Espacio Abierto de Televisoras Populares, Alternativas y Comunitarias se constituyó para oponerse a las políticas gubernamentales en materia de comunicación, lo que restringe sus posibilidades de acceso a la cooperación estatal.

Esto se puso de manifiesto en los procesos de emergencia de estas entidades y en la trayectoria de sus dirigentes e impulsores. Trama Audiovisual fue impulsada, como ya se mencionó, por la Usina de Medios, iniciativa mixta entre el INAES y Cooperar. Trama se inserta, además, en un espacio más amplio de cooperativas comunicacionales: Coomunicar, entidad también impulsada por Usina de Medios y creada en marzo de 2013 por más de 1,300 cooperativas del sector.

Por su parte, FECOOP-TV fue impulsada por Comunicación y Política en el Proyecto Nacional (COPLA). COPLA se había constituido en agosto de 2009 ante la inminencia del envío del proyecto de la Ley de Servicios de Comunicación Audiovisual al Congreso con el fin de apoyar la iniciativa y luego incidir en la formulación de las consecuentemente nuevas políticas de comunicación (Segura, 2009-2010, p. 119-140). Está conformada por funcionarios de segundo y tercer rango de las áreas de comunicación de diversos organismos estatales, profesionales y militantes del campo comunicacional identificados con el kirchnerismo. Muchos de ellos integran también la Coalición por una Comunicación Democrática y, dentro de ella, constituyen el grupo más afín a los gobiernos de Néstor Kirchner y Cristina Fernández.

\footnotetext{
40 El presidente del Consejo de Administración de FECOOP-TV, Néstor Piccone, es integrante del Consejo Asesor del SATVD-T e integrante de la Mesa de Coordinación de la Coalición por una Comunicación Democrática y de COPLA. Fue gerente de noticias de Radio Nacional (2004), delegado argentino en Telesur (2005), dirigente gremial de la Unión de Trabajadores de la Prensa de Buenos Aires (UTPBA), la Federación Argentina de Trabajadores de Prensa (FATPREN) y la Confederación Sindical de Trabajadores de Medios de Comunicación (COSITMECOS). Por su parte, el síndico de FECOOP-TV, Roberto Gómez, del Instituto Movilizador de Fondos Cooperativos (IMFC), también integra la Coalición desde su fundación. En tanto, el titular del Programa Usina de Medios, Nahum Mirad, fue miembro fundador de Comercio y Justicia Editores La Cooperativa cuando sus trabajadores recuperaron este diario cordobés que había ido a la quiebra en 2001. Se desempeñó como secretario de esta Cooperativa, responsable editorial del diario y presidente de Diarios y Periódicos de la República Argentina (DYPRA).

${ }^{41}$ Por ejemplo, FECOOP-TV fue impulsada desde la sociedad civil aunque algunos de sus integrantes eran funcionarios del gobierno. Esta condición tuvo incluso el efecto de que hubo organizaciones que se sumaron al proyecto suponiendo que era una iniciativa gubernamental y que, por lo tanto, conseguirían mayores recursos económicos. En efecto, les permitió conseguir los recursos necesarios para desarrollar los productos audiovisuales que hicieron hasta el momento (Piccone, 2013). Este financiamiento se obtuvo en forma de subsidio y no por concurso de proyectos porque el reglamento de concursos de SATVD-T prohíbe la inscripción de funcionarios del Consejo Asesor (art. 15).
} 
Además, gran parte de las organizaciones y personas integrantes de FECOOPTV y de Trama Audiovisual forman parte de la Coalición por una Radiodifusión Democrática desde sus comienzos en 2004. La Coalición fue la más amplia alianza conformada por todos los agentes del campo comunicacional que buscaban un cambio democratizador en las reglas de juego del sistema mediático, junto con actores que intervenían en otros ámbitos de lo social (universidades, sindicatos, organismos de derechos humanos, asociaciones de radiodifusores comunitarios, asociaciones de cooperativistas, etc.), quienes lograron consensuar una propuesta integral común (los 21 Puntos por una radiodifusión para la democracia) que se impuso como fundamento de la nueva Ley 26.522. Si bien la Coalición estaba integrada por organizaciones y personalidades de diversos signos políticos, a partir de 2008 estableció una alianza con el Gobierno nacional, primero para impulsar el proyecto de Ley de Servicios de Comunicación Audiovisual y, luego de su aprobación, para reglamentarla, lograr su plena vigencia frente a la interposición de recursos judiciales para evitarlo, e implementarla (Segura, 2011 y 2011a). Además, a partir de 2012, la Coalición reemplazó su modo de organización y decisión asambleario y por consenso, por la constitución de un mecanismo representativo de conducción: la mesa directiva que - como se dijo - integran algunos dirigentes de FECOOP-TV.

No obstante, el movimiento cooperativo -incluso en el sector comunicacional, como muestra el caso de COLSECOR (Cooperativa de Provisión y Comercialización de Servicios Comunitarios de Radiodifusión creada en 1995) y el de CARCO (Cámara Argentina de Radiodifusores Cooperativos constituida en 1997) - tiene una trayectoria de integración y articulación para mejorar sus condiciones y superar las crisis que históricamente se dio con independencia del Estado. Es más: se producía en los lugares y con los servicios públicos donde el Estado se ausentaba y aún a pesar de las normativas estatales que lo impedían, como en la década de 1990 cuando para poder prestar servicios de radiodifusión las cooperativas se transmutaban en sociedades de responsabilidad limitada o sociedades anónimas (COLSECOR, 2013). Después de la crisis de 2001/2002 y a partir de 2003, "ha comenzado una etapa favorable para el cooperativismo, con una política pública de promoción de la economía social” (Tissera, 2013).

Muchas de las televisoras que conforman Espacio Abierto se potenciaron durante el proceso de debate y sanción de la Ley de Servicios de Comunicación Audiovisual, aunque sus proyectos tienen trayectorias anteriores a 2008. Por ejem- 
plo, Barricada TV comenzó a producir informes en 2007, pero en 2009 montaron el estudio en vivo al hacer el acuerdo con IMPA. Algunas tienen estudios con transmisiones en diferido y en vivo, mientras que otras (como TV PTS) transmiten solo por internet. En Barricada TV, por ejemplo, trabajan entre 25 y 30 personas en total, con diferentes niveles de compromiso y tareas (Vinelli, 2013). Como ya se observó, casi todas funcionan en la ciudad de Buenos Aires y en el Gran Buenos Aires, salvo dos. Todas están ligadas de modo no necesariamente orgánico a partidos políticos de izquierda (PTS, PO y Libres del Sur), movimientos territoriales y fábricas recuperadas por sus trabajadores como IMPA (Vinelli, 2013). Algunas de estas televisoras también integran la RNMA.

Por su parte, las productoras audiovisuales que también integran Espacio surgieron entre fines de los 90 y los primeros años de este siglo, cuando acompañaron con sus registros documentales a los actores movilizados que protagonizaron ese período como las asambleas ciudadanas, las organizaciones piqueteras y las cooperativas de trabajadores que recuperaban empresas en quiebra ${ }^{42}$. Estos movimientos sociales, especialmente los dos últimos, mantuvieron una particular relación con el Estado: fueron activos en el reclamo y, una vez obtenidos los recursos, algunos de ellos les dieron un uso cooperativo destinado al desarrollo y fortalecimiento de la organización. Esta trayectoria nos permite comprender las razones por las que Espacio reitere esta toma de posición e inscriba su propuesta de vínculo con el Estado en la tradición de estas experiencias.

Estas trayectorias, así como las propiedades y recursos que controlan y la gestión de sus competencias, permiten interpretar sus tomas de posición con respecto al Estado y su opción por insertarse en la doble tradición de organizaciones sociales y el Estado (FECOOP-TV y Trama Audiovisual) o bien solo la de movimientos sociales (Espacio Abierto).

Como se puede ver, FECOOP-TV y Trama Audiovisual, por un lado, y Espacio Abierto, por otro, constituyen tipos de medios no lucrativos con trayectorias y competencias diferentes que se posicionan de modo también divergente. En 2004,

\footnotetext{
42 A partir de diciembre de 2001, ante la crisis de las políticas neoliberales y de la democracia representativa, la comunicación se tornó necesaria para disputar nuevos sentidos y definiciones del orden social común. La emergencia de nuevos actores sociopolíticos conllevó la necesidad de disputar la visibilidad y los sentidos de la propia identidad y de las demandas para la presentación en el espacio público también mediático. Todo esto hizo que se otorgara cada vez mayor relevancia a la cuestión comunicacional y se la considerase inescindible de las disputas políticas (Segura, 2011, p. 118-119). Sobre la multiplicación de colectivos "contraculturales" que vinculaban arte y política durante las intensas movilizaciones que caracterizaron a este período, véase Longoni, 2005 y Svampa, 2008.
} 
durante una etapa caracterizada por la recuperación institucional del Estado después de la amplia crisis de 2001/2002, la mayoría de los medios del sector social se nucleó o bien en la Coalición por una Radiodifusión Democrática o bien en la Red Nacional de Medios Alternativos (RNMA) ${ }^{43}$.

Estas alianzas produjeron dos tomas de posición que podrían caracterizarse, en términos generales, como la de los medios alternativos con orientación pública y la de los medios alternativos con orientación alternativa ${ }^{44}$. Los primeros impulsan la profundización de la presente democracia mientras que los segundos encuadran sus prácticas de comunicación en el marco de una opción política revolucionaria de izquierda ${ }^{45}$. No obstante, a partir de 2008, durante el debate de las propuestas de nueva ley de radiodifusión, coincidieron en apoyar una nueva normativa que los reconociera como prestadores del servicio. Las diferencias se centraban en la definición del rol del Estado y de sus relaciones con él: mientras la Coalición estableció una alianza con el gobierno, la Red otorgó un apoyo crítico a

\footnotetext{
43 La RNMA se conformó en 2004 con medios que reivindicaban el modelo alternativo y estaban ligados al movimiento de fábricas recuperadas y a organizaciones piqueteras, estudiantiles y sindicales de diversas vertientes de la izquierda. Buscan el cambio social y conciben la comunicación como instrumento para ese fin emancipador. Reivindican la autonomía política, pero saben que es posible en la medida en que esté asegurado el sostén económico. Esto los conduce a tensiones en su relación con el Estado (Segura, 2011).

44 No obstante, en términos de Fraser (1997, p. 17), los dos tipos de prácticas de comunicación alternativa que aquí se consideran tendrían "orientación pública" al intentar disputar en la esfera pública "oficial" con actividades dirigidas a públicos más amplios. Esto supone la confrontación con otros por la redefinición de qué tópicos son considerados públicos, quiénes son los sujetos autorizados para hablar y cuáles son las modalidades expresivas y las condiciones estructurales de propiedad de los medios aceptadas. Estas iniciativas, en la medida en que surgieron como respuesta a exclusiones comunicacionales, contribuyeron a ampliar los límites de la confrontación discursiva (Fraser, 1997, p. 116). La articulación entre "semejantes" que impulsa causas particulares tiene "orientación pública" en tanto pretende trascender lo particular hacia lo "común y general” (Rabotnikoff, 1997, p. 17) por medio de alianzas con "otros diferentes" y propone "representar intereses de las mayorías sociales" (Jaimes, 2010). Así, la búsqueda de masividad de lo alternativo se articula a lo público porque se justifica desde el carácter que lo hace deseable para toda la sociedad (Segura, 2011).

45 En otros términos, Henkel y Morcillo (2013) hacen referencia a dos tradiciones de medios alternativos: los "de vanguardia" y los "de base". En los primeros, la comunicación es concebida como un instrumento en las luchas por la emancipación, mientras que en los segundos, la comunicación contribuye a democratizar las relaciones sociales. Desde otra perspectiva, Mastrini sostiene que en las tomas de posición de la sociedad civil con respecto a los medios públicos sobresalen en Latinoamérica dos que se distinguen entre sí por su visión sobre el Estado. Una establece una relación de desconfianza con el Estado y, por lo tanto, prefiere desarrollar medios alternativos antes que apostar a la construcción de medios públicos. En tanto, la otra sostiene la importancia de que el Estado sea garante del derecho a la comunicación y se preocupa por impulsar medios públicos garantizados por el Estado y que el Estado regule el sistema comunicacional (Mastrini, 2013).
} 
la iniciativa (véase Segura, 2011) ${ }^{46}$. Sin embargo, una vez logrado esto y habiendo cambiado el objeto de la disputa a partir de la entrada en vigencia de la Ley 26.522, las divergencias se acentuaron.

\section{Consideraciones finales}

¿Por qué estos agentes optan por desarrollar estas estrategias? La respuesta a este interrogante articula dos dimensiones, a saber: 1) las características de las prácticas desarrolladas en tanto tomas de posición y 2) la identidad social de los agentes construida a partir de una posición y una trayectoria que, en el marco de ciertas condiciones, determinan su lugar en el sistema.

Como se dijo, las prácticas producidas por estas organizaciones de la sociedad civil se ubican en el nuevo espacio de posibles que configura la Ley de Servicios de Comunicación Audiovisual que establece, entre otros aspectos, la reserva el 33\% del espectro radioeléctrico para las organizaciones sin fines de lucro y una cuota de pantalla para la producción local, nacional, independiente y propia.

Además, sus opciones se vinculan con su lugar de menor poder relativo -en la medida en que constituyen el sector de menores recursos económicos, menor desarrollo institucional, menor visibilidad y cuya actividad era ilegal hasta hace apenas ocho años-, en un mercado históricamente dominado por el sector privado y en el que se registra un reciente fortalecimiento del sector estatal en su rol de productor comunicacional y cultural.

Así, para aumentar su probabilidad de producir y vender contenidos audiovisuales y de prestar servicios de comunicación audiovisual, los tres agentes colectivos analizados optan por cuatro estrategias complementarias:

1) Articularse en una organización de mayor grado (Federación, Espacio);

2) procurar el apoyo económico y el reconocimiento legal del Estado en su rol de regulador de las políticas del área e importante financiador del sistema;

3) visibilizar su inserción social y territorial en la medida en que es un factor que las diferencia de los otros dos sectores de la radiodifusión, y

\footnotetext{
${ }_{46}$ Estas dos tomas de posición de los medios alternativos se vinculan con las posturas de los movimientos sociales (piqueteros, territoriales, de derechos humanos, ambientalistas) y los sindicatos —en particular, las divisiones de sus dos centrales obreras en otras dos, más la multiplicación de sindicalismo de base- con respecto al Estado durante los gobiernos de Kirchner y Fernández: se profundizaron las diferencias preexistentes hasta constituir divisiones que se tradujeron en alianzas con el gobierno - que podrían incluir incorporaciones de dirigentes como funcionarios de segunda o tercera línea- o enfrentamientos (véase: Mauro \& Rossi, 2011; Piccone, 2013; Vinelli, 2013; Castillo, 2011).
} 
4) fortalecer sus capacidades de producción de contenidos audiovisuales y sus estrategias de financiamiento.

No obstante, dentro del sector hay diferencias en las tomas de posición y en las posturas de poder relativo de cada agente colectivo. La gestión de la relación con el gobierno a cargo del Estado, en tanto regulador y controlador del sistema así como financiador relevante, constituye una de las principales estrategias de diferenciación y muestra una clara relación con el lugar, la competencia, la gestión y la trayectoria de cada uno de estos agentes colectivos, en las que se conjugan fortaleza institucional, recursos económicos y tecnológicos, competencias profesionales, relación con partidos políticos e inserción comunitaria y territorial.

Resulta evidente, entonces, que en todos los casos las opciones, además de ser valorativas, se vinculan con las posiciones de poder relativo y las posibilidades de incidencia que tengan los agentes. Así, sus opciones tienen que ver no solo con los principios esgrimidos como fundamentos de las prácticas (la ampliación de derechos, la democratización, etc.), sino también con el estado de las relaciones de fuerza en el sistema comunicacional. Por lo tanto, las disputas por la democratización de las comunicaciones están indisolublemente ligadas a las luchas por la democratización de otras áreas de lo social y son indisociables de las relaciones de fuerza en el proceso social (Cfr. Mata, 2006; Fraser, 2006; Caletti, 2005; Segura, 2011).

\section{Referencias}

AMARC (1990). Programa Mundial de Legislaciones y Derecho a la Comunicación. Disponible en internet y consultado en ago. 2013: http://legislations.amarc.org/es

Baranchuk, M. \& Rodríguez Usé, J. (coords.) (2011). Ley 26.522: hacia un nuevo paradigma en comunicación audiovisual. Buenos Aires: Galerna.

Becerra, M. (2009). "Las cuentas pendientes de los medios". En: La Nación, Buenos Aires, 10 de octubre.

Becerra, M. (2013). “Un ciclo, dos etapas”. En: Miradas al sur. Buenos Aires, 6 (259). Disponible en internet y consultado en ago. 2013: http://sur.infonews.com/notas/un-ciclo-dos-etapas

Becerra, M. \& López, S. (2009, sep.). La contienda mediática: temas, fuentes y actores en la prensa por el conflicto entre el Gobierno y las entidades del campo argentino en 2008. Revista de Ciencias Sociales. Bernal: Universidad Nacional de Quilmes, 2a. época, 16, p. 16-30.

Becerra, M. \& Mastrini, G. (2009). Los dueños de la palabra: acceso, estructura y concentración de los medios en la América del siglo XXI. Buenos Aires: Prometeo.

Berlanga, J. M. (2012). “Otra televisión es posible”. En: Mirad N. et al. (eds.). Economía solidaria hacia un nuevo mapa de la comunicación: textos, contextos, esperiencias y propuestas del cooperativismo y mutualismo (p. 205-224). Buenos Aires: Usina de Medios.

Berlanga, J. M. (2013). Entrevista.

Bourdieu, P. (1997). Razones prácticas. Barcelona: Anagrama. 
Bourdieu, P. (2000). Cosas dichas. Barcelona: Gedisa.

Caletti, S. (2005). "Políticas de comunicación: acentos en debate". En: Loreti, D.; Mastrini, G. \& Baranchuk, M. (comps.). Participación y democracia en la sociedad de la información: actas III Congreso Panamericano de Comunicación (p. 59-67). Buenos Aires: Prometeo.

Calicchio, P. (2011). Garantizar el 33\%, un desafío para el Estado y las organizaciones populares. PNCé. Buenos Aires, 4. Disponible en internet: http://pnce.com.ar/historial/index.php/historial/ pnce-nro4/84-garantizar-el-33-un-desafio-para-el-estado-y-las-organizaciones-populares.html

Calicchio, P. \& Vinelli, N. (2012). "La sustentabilidad de los medios comunitarios". En: Página/12, Buenos Aires, 12 de septiembre.

Castillo, C. (2011). La izquierda frente a la Argentina kirchnerista: una visión alternativa al relato gubernamental y al de los medios opositores. Buenos Aires: Planeta.

Coalición por una Comunicación Democrática (2012). Carta pública. Buenos Aires: CCD.

Coalición por una Comunicación Democrática (2013). "Reunión y avances con el Consejo Federal" y "Presentación y acuerdos con AFSCA", Buenos Aires, marzo de 2012. Disponible en internet y consultado en mayo de 2013: http://coalicionccd.blogspot.com.ar/.

Centro Cultural de la Cooperación (2012). "Cooperativa Trama Audiovisual". En: Cooperativismo en movimiento. Buenos Aires: Centro Cultural de la Cooperación. Disponible en internet: http:// www.centrocultural.coop/blogs/cooperativismo/2012/11/29/cooperativa-trama-audiovisual/

COPLA (2011). Militancia y comunicación. Buenos Aires: COPLA.

Coraggio, J. L. (2007). Economía social, acción pública y política: hay vida después del neoliberalismo. Buenos Aires: CICCUS.

Corbière, F. \& Güida, M. C. (2012). "La judialización de la Ley de Servicios de Comunicación Audiovisual: breve estudio de casos". En: I Coloquio de comunicación para la transformación social, Escuela de Ciencias de la Información, Universidad Nacional de Córdoba, Córdoba, 30 y 31 de agosto de 2012. Disponible en internet: http://www.eci.unc.edu.ar/coloquio40/ponencias/mesa4/ Corbiere-Guida.pdf

Costa, R. L. (2010, jun.). Acerca de la comprensión/explicación: una aproximación desde Max Weber. ConCiencia Social. Córdoba: Editorial Espacio; Escuela de Trabajo Social, Universidad Nacional de Córdoba, nueva época, 10 (13), p. 61-70.

Costa, R. L. \& Mozejko, T. D. (2001a). El discurso como práctica: lugares desde donde se escribe la historia. Rosario: Homo Sapiens.

Costa, R. L. \& Mozejko, T. D. (2001b, dic.). Producción discursiva: el sujeto social y sus simulacros: primera parte. ConCiencia Social. Córdoba: Escuela de Trabajo Social, Universidad Nacional de Córdoba, 1 (1), p. 43-54.

Costa, R. L. \& Mozejko, T. D. (2002, jun.). Producción discursiva: el sujeto social y sus simulacros: segunda parte". ConCiencia Social. Córdoba: Escuela de Trabajo Social, Universidad Nacional de Córdoba, 2 (2), p. 43-52.

Costa, R. L. \& Mozejko, T. D. (2009). Gestión de las prácticas: opciones discursivas. Rosario: Homo Sapiens.

Crettaz, J. (2013). "El 94\% de los medios creados con la nueva ley es estatal". En: La Nación, Buenos Aires, 2 de mayo.

Charaudeau, P. (1982). Langage et discours: eléments de sémiolingüistique (théorie et pratique). Paris: Hachette Université.

Charaudeau, P. (2003). El discurso de la información: la construcción del espejo social. Barcelona: Barcelona.

Fraser, N. (1997). Iustitia interrupta: reflexiones críticas desde la posición "postsocialista". Bogotá: Universidad de los Andes; Siglo del Hombre Editores. 
Fraser, N. (2006). Reinventar la justicia en un mundo globalizado. En: New Left Review, Madrid: Akal, 36.

Henkel, C. \& Morcillo, J. (2013). La palabra liberada: una crítica marxista a la ley de medios. Buenos Aires: EUDEBA.

Iglesias, M. \& Leavi, C. (2013). “En el aire: tensiones en los modelos de gestión de las emisoras comunitarias argentinas en la encrucijada del mercado y la regulación estatal de medios". En: VII Congreso internacional ULEPICC "Comunicación, políticas e industria: procesos de digitalización, crisis, sus impactos en las políticas y la regulación”. Bernal, Universidad Nacional de Quilmes, 10 al 12 de julio.

Jaimes, D. (2010). “¿Comunicación pública alternativa?”. En: Página/12, Buenos Aires, 25 de agosto. Krakowiak, F. (2013). “Con luz verde para transmitir”. En: Página/12, Buenos Aires, 2 de junio.

Longoni, A. (2005). La legitimación del arte político. [Revista] Brumaria. Barcelona?, 5.

Ludueña, M. E. (2010). “Todo o nada... Estado y medios en pie de guerra”. En: Rincón, O. (ed.). ¿Por qué nos odian tanto? Estado y medios de comunicación en América Latina (p. 263-288). Bogotá: Centro de Competencia en Comunicación para América Latina; Friedrich Ebert Stiftung.

Marino, S. (2011). Medios comunitarios y ley: avances, límites y desafíos de un proceso novedoso. PNCé. Buenos Aires, 4. Disponible en internet: http://pnce.com.ar/historial/index.php/historial/ pnce-nro4/82-medios-comunitarios-y-ley-avances-limites-y-desafios-de-un-proceso-novedoso. html

Mastrini, G. (ed.) (2009). Mucho ruido, pocas leyes: economía y políticas de comunicación en la Argentina (1920-2004). Ed. ampl. Buenos Aires. La Crujía.

Mastrini, G. (2010). Entrevista.

Mastrini, G. (2013). "Medios públicos y derecho a la comunicación”. En: Mastrini, G.; Bizberge, A. \& De Charras, D. (eds.). Políticas de comunicación en el siglo XXI. Buenos Aires: La Crujía.

Mastrini, G. \& Becerra, M. (2006). Periodistas y magnates: estructura y concentración de las industrias culturales en América Latina. Buenos Aires: Prometeo.

Mata, M. C. (1999). De la cultura masiva a la cultura mediática. Diálogos de la Comunicación. Lima: FELAFACS, 56, p. 80-91.

Mata, M. C. (2006). Comunicación y ciudadanía: problemas teórico-políticos de su articulación. Fronteiras: estudos midiáticos. São Leopoldo, Brasil: Universidad de Vale do Rio dos Sinos (UNISINOS), 8 (1), p. 5-15.

Mauro, S. \& Rossi, F. M. (2011). "Entre la plaza y la Casa Rosada: diálogo y confrontación entre los movimientos sociales y el gobierno nacional”. En: Malamud, A. \& De Luca, M. (coords.). La política en tiempos de los Kirchner. Buenos Aires: EUDEBA.

Mirad, N. et al. (comps.) (2012). Economía solidaria hacia un nuevo mapa de comunicación: textos, contextos, experiencias y propuestas del cooperativismo y el mutualismo. Buenos Aires: Usina de Medios.

Mozejko, D. T. \& Costa, R. L. (comps.) (2002). Lugares del decir: competencia social y estrategias discursivas. Rosario: Homo Sapiens.

Mozejko, D. T. \& Costa, R. L. (comps.) (2007). Lugares del decir 2: competencia social y estrategias discursivas. Rosario: Homo Sapiens.

Oliva, A. (2008, jul.). Los latifundistas de la comunicación. Proyección. Córdoba: CISPREN, p. 6-8.

Piccone, N. (2011). Entrevista.

Piccone, N. (2011). Comunicación personal.

Piccone, N. (2013). Entrevista.

Rabotnikoff, N. (1997). El espacio público y la democracia moderna. México, D.F.: Instituto Federal Electoral. 
Sabbatella, M. (2013). Informe de gestión: primer semestre. Buenos Aires: Autoridad Federal de Servicios de Comunicación Audiovisual (AFSCA). Disponible en internet: http://www.afsca.gob. $\operatorname{ar} / 2013 / 05 /$ informe-de-gestion-primer-semestre-de/.

Salerni, L. (2012). "Introducción". En: Mirad N. et al. (eds.). Economía solidaria hacia un nuevo mapa de la comunicación: textos, contextos, esperiencias y propuestas del cooperativismo y mutualismo (p. 19-21). Buenos Aires: Usina de Medios.

Segura, M. S. (2009-2010). Democratizar las comunicaciones en Argentina: las estrategias de las organizaciones sociales, 2001-2010. Revista Argentina de Comunicación. Buenos Aires: Prometeo, 4, p. 4-5.

Segura, M. S. (2011). Las disputas por democratizar las comunicaciones: las tomas de posición de las organizaciones sociales: Córdoba, 2001-2009 [tesis]. Buenos Aires: doctorado en Ciencias Sociales, Universidad de Buenos Aires.

Segura, M. S. (2011a). La sociedad civil y la democratización de las comunicaciones en la Argentina: la experiencia de la Coalición por una Radiodifusión Democrática. Argumentos: revista electrónica de crítica social. Buenos Aires: Universidad de Buenos Aires. Facultad de Ciencias Sociales. Instituto Gino Germani, 13. Disponible en internet: http://revistasiigg.sociales.uba.ar/index.php/ argumentos/article/view/141.

Sodré, M. (1998). Reinventando la cultura: la comunicación y sus productos. Barcelona: Gedisa.

Sorj, B. (comp.) (2010). Poder político y medios de comunicación: de la representación política al reality show. Buenos Aires: Siglo XXI.

Szpolski... (2010). "Szpolski, el 'socio' dilecto de los K”. En: Clarín, Buenos Aires, 20 de junio.

Svampa, M. (2008). Cambio de época: movimientos sociales y poder político. Buenos Aires: Siglo XXI; CLACSO.

Tissera, P. (2013). "Alta Gracia: cooperativismo y periodismo autogestionado". En: Colsecor noticias, 10 de junio. Disponible en internet: http://colsecornoticias.com.ar/index. $\mathrm{php} / 5230$-alta-gracia-cooperativismo-y-periodismo-autogestionado.

Verón, E. (1980). “Discurso, poder, poder del discurso". En: Anais do primeiro Colóquio de semiótica (p. 85-97). Rio de Janeiro: Pontifícia Universidade Católica (PUC); Edições Loyola.

Verón, E. (1987). "La palabra adversativa: observaciones sobre la enunciación política”. En: Verón, E. et al. El discurso político: lenguajes y acontecimientos (p. 13-26). Buenos Aires: Hachette.

Verón, E. (1998). "Interfaces sobre la democracia audiovisual evolucionada”. En: Ferry, J.-M.; Wolton, D. et al. El nuevo espacio público (p. 124-139). Barcelona: Gedisa.

Vinelli, N. (2011). "Por una televisión alternativa y masiva". En: Vinelli, N. (comp.). Comunicación $y$ televisión popular: escenarios actuales, problemas y potencialidades (p. 11-35). Buenos Aires: El Río Suena.

Vinelli, N. (2013). Entrevista.

\section{Contacto}

\section{María Soledad Segura}

sole_segura@yahoo.com.ar 